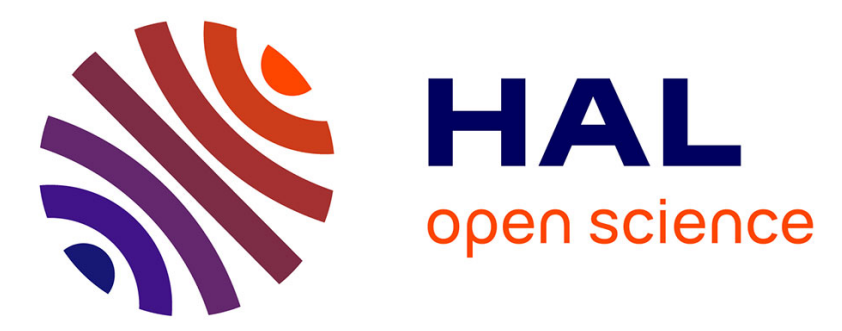

\title{
Collembolan preferences for soil and microclimate in forest and pasture communities
}

Charlène Heiniger, Sébastien Barot, Jean-François Ponge, Sandrine Salmon, David Carmignac, Margot Suillerot, Florence Dubs

\section{To cite this version:}

Charlène Heiniger, Sébastien Barot, Jean-François Ponge, Sandrine Salmon, David Carmignac, et al.. Collembolan preferences for soil and microclimate in forest and pasture communities. Soil Biology and Biochemistry, 2015, 86 (April), pp.181-192. 10.1016/j.soilbio.2015.04.003 . hal-01147855

\section{HAL Id: hal-01147855 \\ https://hal.science/hal-01147855}

Submitted on 2 May 2015

HAL is a multi-disciplinary open access archive for the deposit and dissemination of scientific research documents, whether they are published or not. The documents may come from teaching and research institutions in France or abroad, or from public or private research centers.
L'archive ouverte pluridisciplinaire $\mathbf{H A L}$, est destinée au dépôt et à la diffusion de documents scientifiques de niveau recherche, publiés ou non, émanant des établissements d'enseignement et de recherche français ou étrangers, des laboratoires publics ou privés. 


\section{Collembolan preferences for soil and microclimate in forest and}

\section{2 pasture communities}

3 Charlène Heiniger ${ }^{\mathrm{a}}$, Sébastien Barot ${ }^{\mathrm{b}}$, Jean-François Ponge ${ }^{\mathrm{c}^{*}}$, Sandrine Salmon ${ }^{\mathrm{c}}$, Jacques

4 Meriguet $^{\mathrm{d}}$, David Carmignac ${ }^{\mathrm{d}}$, Margot Suillerot ${ }^{\mathrm{a}}$, Florence Dubs ${ }^{\mathrm{a}}$

$5 \quad{ }^{\mathrm{a}}$ IRD, UMR BIOEMCO, Centre France Nord, 93143 Bondy, France

$6 \quad{ }^{\mathrm{b}}$ IRD, UMR BIOEMCO, ENS. 75006 Paris, France

${ }^{\mathrm{c}}$ MNHN-CNRS, UMR 7179, 91800 Brunoy, France

8

${ }^{\mathrm{d}}$ ENS, UMR BIOEMCO, ENS. 75006 Paris, France

9 Key words: collembolan communities, habitat preference, forest and pasture soil, microclimate effect, field experiment

11

\section{Abstract}

The goal of the present study was to determine whether the habitat preference of collembolan species is more influenced by soil properties or by microclimate and whether the preference for a given soil matches the preference for the corresponding microclimate. To answer these questions, we set up a soil core transfer experiment between a forest and an adjacent pasture. We first eliminated the entire soil fauna from forest and pasture soil cores and inoculated them with a new community originated from forest or pasture. After enclosing them, in order to prevent exchanges of soil animals between treated soil and surrounding environment, soil cores were transplanted back to the field for four months and a half. The experimental design comprises every combination of three factors (community origin, soil nature and microclimate) for a total of 8 treatments. Twenty-two species were present in the experiment, 16 of which were present in more than $10 \%$ of the experimental soil cores. We determined habitat preference for these 16 species using a large dataset comprised of field observations in the same region. Results showed that most forest species did not withstand pasture

\footnotetext{
${ }^{*}$ Corresponding author. Tel. : + 33678930133

E-mail address : ponge@mnhn.fr (J.F. Ponge)
} 
microclimate, although some of them preferred pasture soil. Likewise several pasture species were favoured by the forest microclimate, some of them also preferring forest soil. We concluded that forest species were absent (or less abundant) in pastures because they are not resistant enough to drought, while pasture species were absent (or less abundant) in forests because of food requirements, and/or soil physicochemical properties such as soil pH and organic carbon content, and/or were less competitive. Moreover, when selecting their habitat, some species are submitted to a trade-off between preferences for different habitat features.

\section{Introduction}

The search for unifying principles in community ecology led to the identification of three processes that interact to shape species assemblages: 1) habitat selection, 2) dispersal and 3) biotic interactions (Weiher and Keddy, 2001; Wardle, 2006; Mayfield et al., 2009). Understanding the factors that determine the preference of a species for a given habitat is thus essential to predict species distribution and local community composition. In most habitats, many different factors (biotic and abiotic) interact, creating environmental conditions that allow or impede species persistence and reproduction (Bull et al., 2007). Furthermore, different species show different levels of specialization for a given habitat, from specialists which are only found in a restricted array of environmental conditions to generalists which are found in a wide array of environmental conditions (Egas et al., 2004; Julliard et al., 2006). The extent to which a species is specialist of a given habitat probably depends on how much it is adapted to the different habitat features and the level of specialization is likely to differ between habitat features.

For invertebrate species inhabiting soil and litter layers, habitat is at least twofold. First, the nature of the soil and the humus form are very influential: (1) they determine the availability and quality of resources such as organic matter, which in turn determines the composition and activity of microbial communities, one of the main food sources of soil invertebrates (Ponge, 1991; Murray et al., 2009; Sabais et al., 2011); (2) soil and humus through several physicochemical properties, such as pH, moisture, structure, carbon content, etc., are critical parameters for collembolan survival (Ponge, 1993; Berg et al., 1998; Loranger et al., 2001). Second, the type of vegetation is also influential: (1) it 
influences the quality and quantity of organic matter inputs; (2) it influences the local microclimate and interacts with soil and humus to determine temperature and moisture levels which prevail within the soil (Chen et al., 2008; Ponge, 2013). For example tree canopy cover in forests prevents most UV radiation from reaching the ground surface and creates lower soil temperatures in forests compared to pastures (Scott et al., 2006).

Collembolan communities have been shown to vary according to vegetation types, e.g. open vs closed vegetation (Ponge et al., 2003; Vanbergen et al., 2007). Forests (closed vegetation) benefit from high inputs of litter which create thick organic (and organic-mineral) layers. High soil carbon content induces both low $\mathrm{pH}$ and high soil moisture and creates conditions favouring overall collembolan abundance and diversity (Hopkin, 1997). In addition, high organic inputs in forests provide abundant trophic resources. In contrast, open vegetation (e.g. any habitat without trees such as pastures or meadows) is characterized by intense export through mowing, grazing, or harvesting, and more active decomposition, which induces lower organic contents and reduced or absent organic layers (Compton and Boone, 2000). Additionally, the absence of tree cover induces higher temperatures in summer and lower soil moisture than in forests (Batlle-Aguilar et al., 2011). Thus, in collembolan communities, specialists of a given habitat should be intolerant to at least one feature of non-preferred habitats (microclimate, resource quality and/or availability, physicochemical factors): for example, forest specialists should be intolerant either to soil properties or microclimate of open habitats. In contrast, generalist species should be generalist for both soil and microclimate.

In their experiment, Auclerc et al. (2009) determined habitat preference and dispersal ability of a large set of collembolan species. Using a soil transplant experiment between a forest and a meadow, they showed that several forest-preferring and forest-strict species actually colonized more efficiently meadow soil transferred to forest than non-transferred forest soil. They suggested that certain forest species, more abundant in the transplanted meadow soil, could not survive in the meadow because of its microclimate. However, in their study the effect of species ability to colonize both soil types through dispersal was difficult to distinguish from the effects of actual preferences for a given habitat. Moreover, Auclerc et al. (2009) only transplanted soil cores from one type of habitat to another but did not submit collembolan communities to a different microclimate. This did not allow a full 
disentanglement of the effects of soil and humus nature from the effects of microclimate determined by plant cover.

The present experiment thus aimed at addressing the two following questions. Are forest or pasture species excluded from (or less abundant in) pastures and forests, respectively, because they do not withstand differences in temperature and related soil moisture (microclimate) in these habitats, or because they do not find appropriate trophic resources and suitable physicochemical conditions (soil nature)? Are generalist species tolerant to both soil and microclimate? We hypothesize that forest and pasture species are not primarily influenced by the same habitat features. Forest species would be absent (or less abundant) in pastures because of physiological requirements for forest microclimate (i.e. higher humidity and lower temperature) whereas pasture species would be absent (or less abundant) in forests because they do not find appropriate trophic resources in them.

Given our choice of a transfer experiment in which animals cannot freely move to find suitable conditions for their growth and reproduction, preferences will be only inferred from their ability to survive and multiply better under certain conditions than others. This is also the sense given to the word "affinity" in similar experiments (Huhta, 1996) but we here refer to the definition given by Pey et al. (2014) of "ecological preference" as "the optimum and/or the breadth of distribution of a trait on an environmental gradient”, considering "ecological preference” as the result of multiple interacting ecophysiological traits each species display and "habitat preference” as a subset of "ecological preference.

\section{Material and methods}

\subsection{Study site}

The study was set up in a forest and an adjacent pasture in the Morvan Regional Natural Park at the same location as the experiment reported in Auclerc et al. (2009). The Morvan Natural Park is located in the centre of France (Burgundy) and has a submontane-atlantic climate with continental influence (mean annual rainfall $1000 \mathrm{~mm}$ and mean temperature $9 \mathrm{C}$ ). The bedrock is granite and soils are moderately to strongly acidic $(\mathrm{pH}<5)$. The forest canopy is comprised of deciduous trees (Fagus sylvatica and Quercus petraea) and has been in place over at least a century, according to stand 
structure. The forest soil is an Acrisol and the humus form is a dysmoder sensu Brêthes et al. (1995).

The nearby pasture used to be mowed every year in spring and then grazed by cattle in summer and autumn, but mowing had been abandoned for several years because of poor forage production due to several consecutive drought years. The pasture soil is a Cambisol and the humus form is an eumull. The transition between forest and pasture is sharp.

\subsection{Experimental design and soil core manipulation}

We designed a soil core transplantation experiment between forest and pasture (closed vs. open vegetation, respectively) coupled with a manipulation of invertebrate communities. Eight treatments (five replicates each) corresponded to all possible combinations of three factors: community origin, COM (forest vs. pasture), soil origin, S (forest vs. pasture) and microclimate, CLIM (forest vs. pasture) (Fig. 1, see also Fig. 2 for a global view of manipulation steps). The setup took place between March and June 2011 (fauna removal, inoculation and transplantation) and the experiment ended in the beginning of November 2011.

\subsubsection{Fauna removal and re-inoculation}

In order to control the communities present in both soils (forest and pasture), we first removed the fauna and re-inoculated it with a new community extracted from a fresh soil core. This allowed us to have a forest community in the pasture soil and conversely a pasture community in the forest soil. Thirty soil cores (20 cm diameter x $10 \mathrm{~cm}$ depth) were taken in both forest and pasture (60 soil cores in total, i. e. the soil, including the soil biota, was sampled by taking of soil samples) and brought back to the laboratory. Soil fauna was then eliminated by repeatedly freezing soil cores. Each soil core was dipped in liquid nitrogen for $45 \mathrm{~min}$. This was repeated after a week interval, in order to eliminate possible resistant eggs that could have been stimulated to hatch by the first freezing. In between, soil cores were stored in a cold chamber at $15^{\circ} \mathrm{C}$.

We then inoculated each soil core with a new community. To do so, 48 soil cores (24 for each soil) of the same volume (20 cm diameter x $10 \mathrm{~cm}$ depth) were taken at the same site. These cores were split into four equal parts in the field, packed into semi waterproof bags (plastic bags with holes 
allowing gas exchanges) and brought back to the lab within two days. They were immediately stored in a cold chamber at $15{ }^{\circ} \mathrm{C}$ before being used as a new community source for re-inoculation. Fourteen defaunated pasture soil cores were inoculated with a community originating from the pasture (4 of which were used as controls, see following section) and 10 pasture soil cores were inoculated with a community originating from the forest. Likewise, 14 defaunated forest soil cores were inoculated with a community originating from the forest ( 4 of which were used as controls, see following section) and 10 forest soil cores were inoculated with a community originating from the pasture. To re-inoculate communities, we used a Berlese dry-funnel extractor. We placed the fresh soil on the extractor sieve and the soil core which had been previously defaunated under it. This procedure allowed transferring the new community from the fresh to the defaunated soil core. Each quarter of the fresh cores was left one week on the extractor sieve. Re-inoculation thus lasted 4 weeks. Each week, one quarter of the soil cores used for re-inoculation was placed on the extractor sieve after the previous quarter was removed. Soil cores were watered every week with $100 \mathrm{~mL}$ distilled water. After fauna removal and before reinoculation, we watered all soil cores with a soil suspension (10 g of soil sampled the same day per litre distilled water) sieved to $20 \mu \mathrm{m}$. Pasture and forest soil cores were watered with a soil suspension prepared with pasture and forest soils, respectively. This procedure was performed in order to reestablish the microbial community in soil cores after fauna removal (freezing).

\subsubsection{Soil core enclosure and transplantation to the field}

In order to prevent as much as possible exchanges of soil animals between treated soils and the surrounding environment, soil cores were enclosed in PVC pipes covered with a $350 \mu \mathrm{m}$ mesh at their top and a $20 \mu \mathrm{m}$ mesh at their bottom. We finally brought the 46 manipulated soil cores back to the field. Each soil-community treatment was transplanted both in the forest and in the pasture and was left in the field from June 15 to November 2, 2011 (four and a half months).

The experimental design thus comprised every combination of three factors (community origin, soil and microclimate) for a total of 8 treatments with 5 replicates each (Fig 1). Additionally, it included 3 types of manipulation controls and 2 types of natural references (3 to 5 replicates depending on the type of control, see next section). 


\subsubsection{Experimental controls and natural references}

At each stage of the experimental setup, controls were implemented. This allowed us to assess the efficiency of: 1) fauna removal, 2) community re-inoculation, 3) exclosure, and allowed us to determine the composition of forest and pasture communities in a non-manipulated situation.

To check for the efficiency of fauna removal, we randomly selected 3 soil cores of each soil directly after fauna removal and we performed fauna extraction (fauna removal controls).

To check for the efficiency of community re-inoculation, 8 soil cores ( 4 forest and 4 pasture cores inoculated with their own community) were randomly selected directly after re-inoculation and placed in a Berlese dry-funnel extractor (inoculation controls).

To check for the efficiency of exclosure, 6 soil cores (3 for each soil) were randomly selected and directly enclosed after fauna removal (i. e. without inoculation with a fresh community) and brought back to the field for transplantation (exclosure controls).

In order to determine the composition of both communities in the undisturbed (i.e. nonmanipulated) situation, 3 samples (5 $\mathrm{cm}$ diameter $\mathrm{x} 10 \mathrm{~cm}$ depth) were taken at the same time in each habitat (forest and pasture) when sampling for the soil material used to re-inoculate experimental soil cores (natural control $t_{0}$ ). They were brought back to the laboratory on the same day for fauna extraction. Likewise, 5 samples (5 cm diameter x $10 \mathrm{~cm}$ depth) were taken in each habitat (forest and pasture) at the end of the experiment and brought back to the laboratory within three days for fauna extraction (natural controls $t_{\text {end }}$ ).

All fauna extractions were performed using a Berlese dry-funnel apparatus and lasted 12 days.

\subsection{Soil sample treatments}

At the end of the experiment, we sampled each core according to three methods. First, a sample $6.3 \times 6.3 \times 10$ (depth) cm was taken at the centre of each core for fauna extraction (fauna samples). Second, a 300-g sample was taken in each core, air dried and sieved (2 mm) for soil analysis (soil $\mathrm{pH}_{\text {water }}$, total carbon, and total nitrogen content by gas chromatography). And third, another 300-g sample was taken in each core and immediately packed in waterproof bags for soil moisture measurements. 
Fauna samples were brought back to the lab within three days and placed in a Berlese dry-

funnel extractor for 12 days. Animals were collected and stored in $70 \%$ ethyl alcohol until identification. Collembola were mounted, cleared in chloral-lactophenol and identified to species level under a light microscope (magnification x 400), according to Hopkin (2007), Potapov (2001), Thibaud et al. (2004) and Bretfeld (1999). Due to the very large number of individuals belonging to this species group, we pooled the two species Folsomia quadrioculata and F. manolachei together.

\subsection{Calculation of species overall habitat preference}

The two ecological traits describing the habitat preference (IndF and IndA, see below) of each species were calculated using the IndVal index (Dufrêne and Legendre, 1997) adapted to the measurement of preference for a given habitat type by Auclerc et al. (2009). For this calculation, we used the data set produced in Ponge et al. (2003), who worked in exactly the same region. One species present in our study (Detriturus jubilarius) was absent from the study by Ponge et al. (2003). The habitat preference of this species was assessed according to expert knowledge (Salmon, unpublished data).

The IndVal index combines the specificity of a species for a habitat type (maximized when the species is found only in a given habitat) and its fidelity to this habitat (maximized when the species is found in all samples of a given habitat):

$$
\operatorname{Ind}_{i j}=\mathrm{A}_{i j} * \mathrm{~B}_{i j} * 100 \text {, where }
$$

$\mathrm{A}_{i j}=$ average abundance of species $i$ in samples of habitat $j$ divided by the average abundance of species $i$ in all samples.

$$
\mathrm{B}_{i j}=\text { number of samples of habitat } j \text { where the species is present divided by the total number }
$$

of samples of habitat $j$.

Ind $_{i j}$ ranges from 0 , when species $i$ is absent from habitat $j$, to 100 (its maximum value), when species $i$ is present in all samples of habitat $j$ and absent in all other habitat samples. We thus obtained two 
IndVal values for each species, one for forest (IndF) and one for agricultural land (IndA). Classes of habitat preference were then determined using the IndVal values IndF and IndA for each species. Species present in both habitat types and having a ratio IndF/IndA (or the reverse) higher or equal to 0.25 were classified as "generalists". Species having a ratio IndA/IndF lower than 0.25 were classified as "forest-preferring" and species having a ratio IndA/IndF $=0$ were classified as "strict forest" species. Species having a ratio IndF/IndA lower than 0.25 were classified as “agricultural-preferring” and species having a ratio IndF/IndA = 0 were classified as "strict agricultural" species (sensu Auclerc et al., 2009).

\subsection{Data analyses}

\subsubsection{Assessing the effect of experimental manipulation}

In order to detect possible effects of soil manipulation, inoculation, and exclosure on species abundance, we implemented linear models testing the effect of control type (natural controls $t_{0}$ and $t_{\text {end, }}$ inoculation control, exclosure control, and experimental control, i.e. treated soil cores transplanted in their own microclimate with their own community), habitat type (forest vs. pasture) and the interaction between these factors, on total abundance (type III sum of squares used for unbalanced design). As the soil volumes sampled for natural controls ( $\mathrm{t}_{0}$ and $\mathrm{t}_{\mathrm{end}}$ ) and experimental controls were different, we transformed the total abundance into areal density (number of individuals per $\mathrm{m}^{2}$ ). To fulfil linear model assumptions, areal density was log-transformed. In order to compare community structure and composition of all types of controls (natural controls $t_{0}$ and $t_{\text {end }}$, inoculation control, exclosure control, and experimental control), we performed a principal component analysis using abundances of common species (i.e. present in at least $10 \%$ of the experimental cores).

In order to detect the effects of experimental treatments on soil properties (total carbon and nitrogen content, soil pH and moisture) we implemented linear and generalized linear models (Gamma link function) testing the effect of soil nature (forest vs. pasture) and microclimate (forest vs. pasture) on soil properties. Data for total carbon and nitrogen content and for soil moisture were logtransformed to fulfil linear model assumptions. 


\subsubsection{Effect of experimental treatments on collembolan diversity and abundance}

In order to detect the effects of experimental treatments on collembolan diversity and abundance, we tested the effect of the three experimental factors (origin of the community, soil nature and microclimate) and the interaction between these factors on species richness, Shannon diversity index, and total abundance using linear models. Abundances were log-transformed to fulfil linear model assumptions. Models were tested after a procedure of automatic model selection based on AIC criterion (stepwise procedure). Combinations of experimental treatments were compared using least square means and associated multiple comparisons of means (Tukey).

\subsubsection{Effect of experimental treatments on collembolan community structure and species abundance}

In order to detect the effect of experimental treatments on community structure, we implemented a between-group multivariate analysis (Baty et al., 2006) on abundances of common species in each treatment. Between-group analysis is a particular case of instrumental variables methods where a single qualitative variable is accounted for (Baty et al., 2006), providing the best linear combination of variables maximizing between-group variance. Between-group analysis was performed using a combination of the three experimental factors (origin of the community COM, soil nature $\mathrm{S}$ and microclimate CLIM, 8 combinations) as the explanatory variable. The significance of the composite factor COM/S/CLIM was tested using a Monte-Carlo permutation test (999 permutations). The effects of experimental factors (COM, S, CLIM and all possible interactions) on the abundance of each common species (i.e. species present in at least $10 \%$ of the experimental cores) were tested using generalized linear models (poisson link function) after a procedure of automatic model selection based on AIC criterion (stepwise procedure). Combinations of experimental treatments were compared using least square means and associated multiple comparisons of means (Tukey). Based on the results of these models, we classified species according to their response to experimental factors. Species being significantly more abundant in a given soil and/or microclimate were considered as preferring this soil and/or microclimate. Species showing similar preferences for soil nature and microclimate were grouped together. 
All statistical analyses were performed using vegan, ade4, car, and lsmeans packages of $\mathrm{R}$ software (R Development Core Team, 2010).

264

265

266

267

268

269

270

271

272

273

274

275

\section{Results}

\subsection{Experimental controls}

In total, 28 species were found (controls included), of which 22 species were present in the experimental treatments (controls excluded). Among these 22 species, 6 were present in less than $10 \%$ of the experimental soil cores ( $<4$ cores) and were thus excluded from the analysis for improving robustness of the conclusions. Among the 16 species kept for the analysis, 9 were also present in exclosure controls. Among these 9 species, four were present in both pasture and forest exclosure controls (Lepidocyrtus lanuginosus, Mesaphorura macrochaeta, Parisotoma notabilis and Sphaeridia pumilis), four were present in pasture exclosure controls only (Brachystomella parvula, Isotoma viridis, Protaphorura armata and Sminthurides schoetti) and one species was present in forest exclosure controls only (Xenylla tullbergi) (Table 1). Thirteen species were successfully inoculated in the experimental soil cores, among them four species were successfully inoculated in both forest and pasture soils, seven were inoculated in forest soil only and two were successfully inoculated in pasture soil only (Table 1). No Collembola were found in the fauna removal control either in pasture or forest soil.

The linear model testing the effect of treatments on collembolan density showed that the type of control (natural controls $t_{0}$ and $t_{\text {end }}$, inoculation control, exclosure control, and experimental control) and the interaction between control type and soil nature exerted an influence on collembolan density ( $<<0.001$ and $\mathrm{p}<0.01$, respectively). Collembolan density was significantly higher in inoculation controls and in experimental controls than in natural controls taken at the end of the experiment ( $\left.\mathrm{t}_{\mathrm{end}}\right)$ (Fig. 3). Additionally, post-hoc tests (Tukey) showed that the natural control taken at the end of the experiment $\left(\mathrm{t}_{\mathrm{end}}\right)$ in the pasture showed a lower collembolan density than both forest and pasture experimental controls. It also showed a lower density than the natural controls taken at the end of the experiment in the forest and than exclosure and inoculation controls in the pasture (Fig 3). The first two axes of principal component analysis (PCA) implemented on species abundances of controls (Fig. 
4) extracted $34.5 \%$ of the total variance ( $29.4 \%$ and $15.1 \%$, respectively). PCA showed that communities were distinguished according to community origin on axis 1, pasture communities standing on the positive side and forest communities standing on the negative side of axis 1 . However, the exclosure control in the forest (TexF) displayed communities closer to the pasture on axis 1 . The community in the forest experimental control (FFF) lay close to the community of forest natural reference both at the beginning and at the end of the experiment. In contrast, the community of the pasture experimental control (PPP) lay close to the community of the pasture natural reference at the end of the experiment but far from the one present at beginning of the experiment.

\subsection{Effects of experimental treatments on soil physicochemical properties}

Linear and generalized linear models (Table 2) testing the effect of soil nature (forest vs. pasture) and microclimate (forest vs. pasture) on soil properties (total carbon and nitrogen content, soil $\mathrm{pH}$ and moisture) showed that the total carbon content was higher in forest than in pasture soil. In contrast, the total nitrogen content did not differ with soil nature or microclimate. Soil pH was higher in pasture than in forest soil $(\mathrm{p}<0.001)$ and soil $\mathrm{pH}$ in pasture soil was higher under forest than under pasture microclimate $(\mathrm{p}<0.001$, Fig. $5 a)$. Soil moisture was significantly affected both by soil nature and microclimate $(\mathrm{p}<0.001$, and $\mathrm{p}<0.01$ respectively). Soil moisture was higher in forest than in pasture soil and soil moisture in pasture soil was higher under forest than under pasture microclimate (Fig. 5b).

\subsection{Effects of experimental treatments on collembolan diversity and abundance}

Linear models testing the effect of the three experimental factors (origin of the community, soil nature and microclimate) on species richness, Shannon index, and total abundance (Table 3) showed that the three factors (community origin, soil nature and microclimate) had an effect on total abundance ( $\mathrm{p}<0.01, \mathrm{p}<0.05$, and $\mathrm{p}<0.001$, respectively). Collembola were more abundant in the pasture than in the forest community (community origin), they were also more abundant in the pasture than in the forest soil, but they were more abundant under forest than under pasture microclimate (Fig. 6a). Only the origin of the community exerted an effect on species richness $(p<0.001)$. The community 
originating from the forest displayed higher species richness than the community originating from the pasture, whatever the microclimate or the soil in which they were inoculated (Fig. 6b). Finally, these models showed that community origin, soil nature, and the interaction between community origin and microclimate had a significant effect on the Shannon index $(\mathrm{p}<0.001, \mathrm{p}<0.01$, and $\mathrm{p}<0.01$ respectively). The Shannon index was higher in forest than in pasture community and was also higher in forest than in pasture soil. Post-hoc tests (Tukey) showed that the interaction between community origin and microclimate was due to the fact that the Shannon index was higher under forest than under pasture microclimate, but only for the community originating from the pasture (Fig. 6c).

\subsection{Effects of experimental treatments on collembolan community structure and species abundance}

The individual response to experimental treatments of the 16 most common species is shown in the Appendix. Between-group analysis (Fig. 7) performed on species abundances taking a combination of community origin, soil nature, and microclimate as the explanatory variable extracted $56 \%$ of the total variance. Axes 1 and 2 accounted for $44 \%$ and $23 \%$ of the variance extracted, respectively. Nine species contributed to the formation of axis 1 , four on the positive side (Protaphorura armata, Parisotoma notabilis, Mesaphorura macrochaeta and Pseudosinella alba) and five on the negative side (Folsomia spp., Isotomiella minor, Detriturus jubilarius, Megalothorax minimus and Friesea truncata). Axis 1 discriminated communities according to their origin, pasture on the positive side and forest on the negative side. Only three species mostly contributed to the formation of axis 2, all of them negatively (Sminthurides schoetti, Isotoma viridis and Xenylla tullbergi). Axis 2 discriminated forest communities according to the microclimate in which they were transplanted, forest microclimate on positive side and pasture microclimate on negative side. For the pasture community, treatments were much less discriminative on axis 2 than for the forest community. A Monte-Carlo permutation test showed that the composite factor COM/S/CLIM significantly affected the community ( $\mathrm{p}=0.001)$. 
3.5. Species classification based on the effect of experimental treatments on species abundance

Using generalized linear models testing the effect of the three factors COM, S, and CLIM on species abundance, we classified species into six groups according to their response to the factors (Table 1). Group A was comprised of three species (Isotomiella minor, Megalothorax minimus, and Pseudosinella mauli) that were more abundant in forest community, soil and microclimate. They were labeled "true forest species" (Fig 8a). Group B was comprised of three species (Folsomia spp., Friesea truncata and Detriturus jubilarius), that were more abundant in both forest community and microclimate, but were more abundant in pasture soil (Fig. 8b). They were labeled “forest species preferring pasture soil”. Species of groups A and B were classified as forest species except Folsomia spp. that were classified as generalists using the IndVal index calculated with the data set produced in Ponge et al. (2003) (Table 1). Group C was comprised of two species (Protaphorura armata and Pseudosinella alba) that were more abundant in the pasture community but more abundant in the forest soil. Additionally, while Protaphorura armata was also more abundant in the forest microclimate (Fig. 8c), microclimate did not exert an effect on the abundance of Pseudosinella alba. Group C was labeled “pasture species preferring forest soil”. Group D was comprised of two species (Mesaphorura macrochaeta and Parisotoma notabilis) which were more abundant both in pasture community and soil but were more abundant in forest microclimate (Fig 8d). They were labeled “pasture species preferring forest microclimate”. Group E was comprised of three species (Brachystomella parvula, Lepidocyrtus lanuginosus, and Sphaeridia pumilis) that were more abundant in pasture microclimate. However, in this group, all three species showed a preference for a different component of the forest habitat, either for soil (Lepidocyrtus lanuginosus) or forest community, i.e. were more abundant in cores inoculated with a forest community (Sphaeridia pumilis), or both components (Brachystomella parvula). Group E was labeled "species preferring pasture microclimate”. And finally, group F was comprised of three species (Xenylla tullbergi, Isotoma viridis and Sminthurides schoetti), that were more abundant in both pasture soil and microclimate. Isotoma viridis (Fig. 8e) and Sminthurides schoetti were as abundant in cores inoculated with a pasture community as in cores inoculated with a forest community whereas Xenylla tullbergi (Fig. 8f) was more abundant in cores inoculated with a forest community. This group was labeled "pasture species". 
Most species of groups C, D, E and F were classified as agricultural and generalist species except for Xenylla tullbergi that was classified as a forest species according to the IndVal index calculated with the data set produced in Ponge et al. (2003) (Table 1).

\section{Discussion}

\subsection{Effect of soil nature and microclimate on collembolan total abundance and community structure}

Our results show that collembolan abundance was higher in forest than in pasture microclimate for both forest and pasture communities. Transplantation decreased the moisture content of forest cores when transplanted in the pasture and it increased the soil moisture of pasture cores transplanted in the forest (Fig. 5b, Table 2). Collembola are known to be sensitive to drought (Vannier, 1987). We thus attribute to this physiological trait the overall abundance increase in forest microclimate and decrease in pasture microclimate. It means that forest species are likely to be absent (or less abundant) in pasture mainly because they survive poorly in pasture climate conditions. This may concern only some stages of collembolan life, such as the moisture-sensitive first stadium, stemming in the incapacity of some species to endure moisture and temperature fluctuations which characterize open environments as opposed to closed environments (Betsch and Vannier, 1977). Additionally, we showed that forest communities were different under pasture and forest microclimate whatever the nature of the soil. This means that microclimate conditions are the first driver shaping collembolan communities in the forest. We thus suggest that forest species display physiological traits (namely poor resistance to drought) that prevent them from surviving or growing larger populations in open habitats. The pasture community did not show such a trend, suggesting that microclimate change (pasture to forest) did not affect its species composition. Thus, microclimate conditions are not likely to be the most important constraint shaping the pasture community.

\subsection{Species preferences for soil and microclimate}

Our experimental design enabled us to unravel species responses to soil nature and microclimate. We showed that some species, classified as forest species according to field occurrence data, are more abundant in forest soil and microclimate and that these species are also more abundant 
in the communities originating from the forest (Group A). These species can thus be regarded as "true forest species” because they need both forest microclimate (moisture, temperature) and soil (food resources and physicochemical properties) to fully develop, at least in the studied region. This is supported by previous experiments showing that I. minor and M. minimus, two out of the three "true forest species” (Group A), are particularly sensitive to drought (Makkonen et al., 2011). However, some other species, also classified as forest species using the large data set from Ponge et al. (2003), are shown to prefer the pasture soil when transplanted to the forest microclimate (Group B). Hence, for these species, preferences for soil and microclimate are not tuned. It means that although they prefer the forest microclimate (temperature and moisture) they prefer trophic resources or physicochemical properties of the pasture soil. Their confinement to forest habitats is thus the result of climate requirements overwhelming soil quality requirements, i.e. least-worst strategy (Berger et al., 2012).

Some authors have already underlined the strong influence of microclimate on Collembola (Lindberg and Bengtsson, 2005; Makkonen et al., 2011; Petersen, 2011). In their experiment, Krab et al. (2010) showed that most species found in a subarctic community tended to select microclimate over substrate quality. Here, we go further and show that some forest species survive better in pasture soil (of mull type) if they can find forest climate conditions. Such conditions (forest microclimate and pasture soil quality) are fulfilled in not or poorly acidic forest soils, as already shown on census basis (but not experimentally demonstrated) by Ponge (1993).

Likewise, we showed that some pasture and generalist species benefit from the forest microclimate (Group D plus Protaphorura armata) but that the abundance of some species decreases when they are transferred to the forest soil (Group D). These species are thus also favoured by higher soil moisture and lower temperature but probably do not find in forest habitat appropriate resources and/or physicochemical features, or are too poorly competitive to maintain populations as large as in the pasture soil. However, pasture species of Group C are more abundant in the forest soil indicating that this soil fulfils their trophic and/or physicochemical requirements. We can thus genuinely ask why these species are more abundant in pasture, given that they seem to be favoured by forest microclimate and soil. Since we eliminated environmental filters (microclimate, soil quality) and dispersal limitation 
421 (eliminated in our experimental design) the answer probably relies in species interactions. Although

422

423

424

425

426

427

428

429

430

431

432

433

434

suspected to explain cases of species richness deficit or species turnover at the local scale (Hågvar, 1990; Winkler and Kampichler, 2000), competition within soil communities is still a too scarcely investigated topic (Bardgett, 2002; Decaëns, 2010). Despite being primarily carried out in laboratory conditions and with a reduced number of species, the few studies trying to shed light on the importance of competition in structuring soil communities suggest that competition occurs and is an important mechanism (Christiansen, 1967; Christiansen et al., 1992; Theenhaus et al., 1999; PostmaBlaauw et al., 2005). Our experiment does not allow directly testing this hypothesis, but our results show that some pasture and generalist species would perfectly withstand and even benefit from forest climate conditions and/or soil quality. This suggests that they are prevented from developing larger populations in forests by forest collembolan species that might be more efficient in exploiting forest resources. To these effects of other members of the collembolan community must be added those of members of a much wider community, the complete trophic network in which Collembola are included, still imperfectly known up to present (Brose and Scheu, 2014). Biotic interactions in which Collembola are dynamically involved include negative interactions such as predation (Lawrence and Wise, 2000), but also positive interactions such as earthworm attraction (Salmon, 2001).

Finally, several species are more abundant under pasture microclimate (Groups E and F). They were all classified as agricultural or generalist species with a single exception: Xenylla tullbergi is the only forest species (present in the original forest community only) that is more abundant in pasture soil and under pasture microclimate. This result may be explained by the fact that Xenylla tullbergi is mostly found in corticolous habitats (Ponge, 1993). It is thus drought tolerant but found more abundantly in trees (absent from agricultural plots such as pasture). Its absence in the pasture community may also result from competition with pasture species. All other species of Groups E and F are agricultural or generalist species that prefer pasture microclimate (Group E) or pasture microclimate and soil (Group F). In Group E, two species were more abundant in the forest soil, which suggests that they either prefer resources found in forest soil or are favoured by higher soil moisture (or other physicochemical properties linked to forest soil) as we showed that under pasture microclimate, soil moisture was higher in the forest than in the pasture soil. We only found two 
species classified as agricultural species that were actually more abundant in pasture soil and under pasture microclimate as supported by previous observations in agricultural habitats (Fratello et al., 1985; Dittmer and Schrader, 2000; Frampton et al., 2001). These two “pasture species” are thus likely to be primarily influenced by microclimate, resources, and soil physicochemical properties rather than by interspecific competition. However, conclusions about Sminthurides schoetti (one of the two abovementioned species) must be drawn with caution. Indeed, this species is the only one that did not succeed in re-inoculated samples but was present in the exclosure controls in the pasture. It is thus present in the experimental soil cores as a pure "invader". Therefore, the preference of this species for pasture or forest microclimate could not be ascertained. However we can be fairly certain that this species preferred the pasture soil as it was more abundant than in the forest soil independently of the community that was present in the soil beforehand.

Our results show that all forest species are better represented under forest microclimate, but that some of them prefer the pasture soil. It means that the most important factor constraining forest species is actually the microclimate. This is probably explained by physiological intolerance of forest species to summer drought. Thus, for some forest species (Group B) habitat preference seems to be the result of a trade-off between physiological requirements and requirements for resources and/or the physicochemical environment.

\subsection{Methodological limitations}

We were not able to fully prevent exchanges between experimental cores and their surroundings. More than half of the species present in more than four experimental soil cores (i.e. common species) invaded the mesocosms. All these species but one were agricultural or generalist species. This means that agricultural and generalist species have a greater mobility than forest species, as they had to climb or jump over the mesocosms in order to penetrate them. This is also partly why forest communities transplanted to pasture microclimate largely differed from forest communities transplanted to forest microclimate. The latter communities were not influenced by species invading from the surrounding pasture. Additionally, soil moisture in pasture soil cores was higher under forest than under pasture microclimate and we showed that total collembolan abundance was also higher in 
pasture experimental control than in natural controls. Thus, microclimate conditions created in the mesocosms seem to overall favour species abundance of the pasture community. Hence some of our results must be interpreted cautiously. First we showed that species richness was not affected by any experimental treatment. Species richness was only lower in the original pasture than in the original forest community. However, the invasion of the forest community by pasture species in microcosms transplanted to the pasture artificially increased species richness. Second, we cannot totally refute that the decrease in the abundance of some forest species under pasture microclimate was due to competitive exclusion from species invading from the surrounding pasture. Besides, we do not know what effects experimental manipulations had on microbial communities. Nevertheless, we were able to successfully re-inoculate most common species despite a long-lasting experimental procedure and to provide responses about soil and microclimate preferences of several collembolan species. This is very encouraging for future experiments dealing with Collembola as more studies are still needed to fully understand mechanisms responsible for patterns of species distribution.

Changes in species composition are known to occur over the year in collembolan communities (Chagnon et al., 2000). Thus in our transfer experiment starting in spring and ending in autumn temporal variability accompanied the effects of microclimate and soil change, and thus could have blurred these effects. This cannot avoided, because expected effects take necessarily some time to appear at community level, through the combination of growth, reproduction, dispersal and species interactions, adding their effects to immediate mortality. However, natural controls, sampled at the beginning and at the end of our transfer experiment, allowed discerning changes in species composition in the meadow while no discernible change occurred in the forest (Fig. 4). Data collected on the same sites in the abovementioned experiment by Auclerc et al. (2009) can be used to support this assessment. A sign-test done on the 16 more common species (unpublished data) showed that over the six months of this experiment (from December to June) the species composition did not change in the forest $($ exact $\mathrm{P}$ value $=0.454)$ while it significantly changed in the meadow $($ exact $\mathrm{P}$ value $=$ 0.021). Thus temporal changes of collembolan populations are probably included in the observed effects of transfer from forest to pasture but not in the reverse case, to the possible exception of species with genetically coded cycles of egg diapause (Leinaas and Bleken, 1983). 


\section{Conclusion}

We showed that habitat preference depends on responses to microclimate and soil quality and that environmental constraints have a different importance depending on the overall habitat preference of species. We conclude that an anthropogenic-induced stress, such as habitat conversion (deforestation or afforestation), modifies collembolan communities to a large extent, and that species show different levels of resistance to perturbations and respond to different constraints (e.g. microclimate, soil, interspecific competition). Generally, forest species seem to be primarily influenced by microclimate, whereas pasture species seem more influenced by trophic resources and competition. This suggests that trade-offs between several habitat constraints are at play and structure collembolan communities in open vs. closed vegetation. More insights into the importance of competition and predation in structuring collembolan communities are still needed at community level.

\section{Acknowledgments}

This study was sponsored by the R2DS program of the Conseil Régional d'Île-de-France. It also received funds from the French Ministry of Ecology, Energy and Sustainable Development (MEEDDM) through the GESSOL 32009 call for projects (TRACES project). We would like to thank the private owner of sampling sites for allowing the study to be carried out on his land. We would like to thank the IRD (Centre France Nord) and the MNHN (Brunoy) for access to their facilities and material; Louis-Cyrille Guillard for his help with performing CHN gas chromatography; Stéphane Sabbe and Marion Meconte for soil pH measurements and their help in sorting fauna material. We would also like to thank Fatima Boucha for her great help in identifying collembolan species and JeanChristophe Lata for his help with the field work as well as Joshua Lobe for English corrections. 


\section{References}

Auclerc, A., Ponge, J.F., Barot, S., Dubs, F., 2009. Experimental assessment of habitat preference and dispersal ability of soil springtails. Soil Biology and Biochemistry 41, 1596-1604.

Bardgett, R.D., 2002. Causes and consequences of biological diversity in soil. Zoology 105, 367-374.

Batlle-Aguilar, J., Brovelli, A., Porporato, A., Barry, D.A., 2011. Modelling soil carbon and nitrogen cycles during land use change. A review. Agronomy for Sustainable Development 31, 251274.

Baty, F., Facompré, M., Wiegand, J., Schwager, J., Brutsche, M.H., 2006. Analysis with respect to instrumental variables for the exploration of microarray data structures. BMC Bioinformatics 7, 422 .

Berg, M.P., Kniese, J.P., Bedaux, J.J.M., Verhoef, H.A., 1998. Dynamics and stratification of functional groups of micro- and mesoarthropods in the organic layer of a Scots pine forest. Biology and Fertility of Soils 26, 268-284.

Berger, D., Olofsson, M., Gotthard, K., Wiklund, C., Friberg, M., 2012. Ecological constraints on female fitness in a phytophagous insect. American Naturalist 180, 464-480.

Betsch, J.M., Vannier, G., 1977. Caractérisation des deux phases juvéniles d'Allacma fusca (Collembola, Symphypleona) par leur morphologie et leur écophysiologie. Zeitschrift für Zoologische Systematik und Evolutionsforschung 15, 124-141.

Bretfeld, G., 1999. Synopses on Palaearctic Collembola. II. Symphypleona. Abhandlungen und Berichte des Naturkundemuseums Görlitz 71, 1-318.

Brêthes, A., Brun, J.J., Jabiol, B., Ponge, J.F., Toutain, F., 1995. Classification of forest humus forms: a French proposal. Annales des Sciences Forestieres 52, 535-546. 
Brose, U., Scheu, S., 2014. 1153Into darkness: unravelling the structure of soil food webs. Oikos 123, 1153-1156.

Bull, J.C., Pickup, N.J., Pickett, B., Hassell, M.P., Bonsall, M.B., 2007. Metapopulation extinction risk is increased by environmental stochasticity and assemblage complexity. Proceedings of the Royal Society of London, Series B, Biological Sciences 274, 87-96.

Chagnon, M., Hébert, C., Paré, D., 2000. Community structures of Collembola in sugar maple forests : relations to humus type and seasonal trends. Pedobiologia 44, 148-174.

Chen, C.R., Condron, L.M., Xu, Z.H., 2008. Impacts of grassland afforestation with coniferous trees on soil phosphorus dynamics and associated microbial processes: a review. Forest Ecology and Management 255, 396-409.

Christiansen, K., 1967. Competition between collembolan species in culture jars. Revue d'Écologie et de Biologie du Sol 4, 439-462.

Christiansen, K., Doyle, M., Kahlert, M., Gobaleza, D., 1992. Interspecific interactions between collembolan populations in culture. Pedobiologia 36, 274-286.

Compton, J.E., Boone, R.D., 2000. Long-term impacts of agriculture on soil carbon and nitrogen in New England forests. Ecology 81, 2314-2330.

Decaëns, T., 2010. Macroecological patterns in soil communities. Global Ecology and Biogeography 19, 287-302.

Dittmer, S., Schrader, S., 2000. Longterm effects of soil compaction and tillage on Collembola and straw decomposition in arable soil. Pedobiologia 44, 527-538.

Dufrêne, M., Legendre, P., 1997. Species assemblages and indicator species: the need for a flexible asymmetrical approach. Ecological Monographs 67, 345-366. 
Egas, M., Dieckmann, U., Sabelis, M.W., 2004. Evolution restricts the coexistence of specialists and generalists: the role of trade-off structure. American Naturalist 163, 518-531.

Frampton, G.K., Van den Brink, P.J., Wratten, S.D., 2001. Diel activity patterns in an arable collembolan community. Applied Soil Ecology 17, 63-80.

Fratello, B., Bertolani, R., Sabatini, M.A., Mola, L., Rassu, M.A., 1985. Effetcs of atrazine on soil microarthropods in experimental maize fields. Pedobiologia 28, 161-168.

Hågvar, S., 1990. Reactions to soil acidification in microarthropods. Is competition a key factor? Biology and Fertility of Soils 9, 178-181.

Hopkin, S.P., 1997. Biology of the Springtails (Insecta: Collembola). Oxford University Press, Oxford.

Hopkin, S.P., 2007. A Key to Collembola (Springtails) of Britain and Ireland. Field Studies Council, Shrewsbury.

Huhta, V., 1996. Community of Mesostigmata (Acari) in experimental habitat patches of forest floor. European Journal of Soil Biology 32, 99-105.

Julliard, R., Clavel, J., Devictor, V., Jiguet, F., Couvet, D., 2006. Spatial segregation of specialists and generalists in bird communities. Ecology Letters 9, 1237-1244.

Krab, E.J., Oorsprong, H., Berg, M.P., Cornelissen, J.H.C., 2010. Turning northern peatlands upside down: disentangling microclimate and substrate quality effects on vertical distribution of Collembola. Functional Ecology 24, 1362-1369.

Lawrence, K.L., Wise, D.H., 2000. Sprider predation on forest-floor Collembola and evidence for indirect effects on decomposition. Pedobiologia 44, 33-39.

Leinaas, H.P., Bleken, E., 1983. Egg diapause and demographic strategy in Lepidocyrtus lignorum Fabricius (Collembola; Entomobryidae). Oecologia 58, 194-199. 
Lindberg, N., Bengtsson, J., 2005. Population responses of oribatid mites and collembolans after drought. Applied Soil Ecology 28, 163-174.

Loranger, G., Bandyopadhyaya, I., Razaka, B., Ponge, J.F., 2001. Does soil acidity explain altitudinal sequences in collembolan communities? Soil Biology and Biochemistry 33, 381-393.

Makkonen, M., Berg, M.P., van Hal, J.R., Callaghan, T.V., Press, M.C., Aerts, R., 2011. Traits explain the responses of a sub-arctic Collembola community to climate manipulation. Soil Biology and Biochemistry 43, 377-384.

Mayfield, M.M., Boni, M.F., Ackerly, D.D., 2009. Traits, habitats, and clades: identifying traits of potential importance to environmental filtering. American Naturalist 174, E1-E22.

Murray, P.J., Clegg, C.D., Crotty, F.V., Martinez, N.d.l.F., Williams, J.K., Blackshaw, R.P., 2009. Dissipation of bacterially derived $\mathrm{C}$ and $\mathrm{N}$ through the meso- and macrofauna of a grassland soil. Soil Biology and Biochemistry 41, 1146-1150.

Petersen, H., 2011. Collembolan communities in shrublands aklong a climatic gradient in Europe and the effect of experimental warming and drought on population density, biomass and diversity. Soil Organisms 83, 463-488.

Pey, B., Nahmani, J., Auclerc, A., Capowiez, Y., Cluzeau, D., Cortet, J., Decaëns, T., Deharveng, L., Dubs, F., Joimel, S., Briard, C., Grumiaux, F., Laporte, M.A., Pasquet, A., Pelosi, C., Pernin, C., Ponge, J.F., Salmon, S., Santorufo, L., Hedde, M. 2014. Current use of and future needs for soil invertebrate functional traits in community ecology. Basic and Applied Ecology. 15, 194-206.

Ponge, J.F., 1991. Food resources and diets of soil animals in a small area of scots pine litter. Geoderma 49, 33-62.

Ponge, J.F., 1993. Biocenoses of Collembola in atlantic temperate grass-woodland ecosystems. Pedobiologia 37, 223-244. 
Ponge, J.F., 2013. Plant-soil feedbacks by humus forms: a review. Soil Biology and Biochemistry 57, 1048-1060.

Ponge, J.F., Gillet, S., Dubs, F., Fedoroff, E., Haese, L., Sousa, J.P., Lavelle, P., 2003. Collembolan communities as bioindicators of land use intensification. Soil Biology and Biochemistry 35, 813-826.

Postma-Blaauw, M.B., de Vries, F.T., de Goede, R.G.M., Bloem, J., Faber, J.H., Brussaard, L., 2005. Within-trophic group interactions of bacterivorous nematode species and their effects on the bacterial community and nitrogen mineralization. Oecologia 142, 428-439.

Potapov, M., 2001. Synopses of Palearctic Collembola. III. Isotomidae. Abhandlungen und Berichte des Naturkundemuseums Görlitz 73, 1-603.

R Development Core Team, 2010. R: a Language and Environment for Statistical Computing. R Foundation for Statistical Computing, Vienna.

Sabais, A.C.W., Scheu, S., Eisenhauer, N., 2011. Plant species richness drives the density and diversity of Collembola in temperate grassland. Acta Oecologica 37, 195-202.

Salmon, S., 2001. Earthworm excreta (mucus and urine) affect the distribution of springtails in forest soils. Biology and Fertility of Soils 34, 304-310.

Scott, N.A., Tate, K.R., Ross, D.J., Parshotam, A., 2006. Processes influencing soil carbon storage following afforestation of pasture with Pinus radiata at different stocking densities in New Zealand. Australian Journal of Soil Research 44, 85-96.

Theenhaus, A., Scheu, S., Schaefer, M., 1999. Contramensal interactions between two collembolan species: effects on population development and on soil processes. Functional Ecology 13, 238246. 
641 Thibaud, J.M., Schultz, H.J., da Gama, M.M., 2004. Synopses on Palearctic Collembola. IV. Hypogastruridae. Abhandlungen und Berichte des Naturkundemuseums Görlitz 75, 1-287.

643 Vanbergen, A.J., Watt, A.D., Mitchell, R., Truscott, A.-M., Palmer, S.C.F., Ivits, E., Eggleton, P., 644 Jones, T.H., Sousa, J.P., 2007. Scale-specific correlations between habitat heterogeneity and 645 soil fauna diversity along a landscape structure gradient. Oecologia 153, 713-725.

Vannier, G., 1987. The porosphere as an ecological medium emphasized in Ghilarov’s work on soil animal adaptations Biology and Fertility of Soils 3, 39-44.

648 Wardle, D.A., 2006. The influence of biotic interactions on soil biodiversity. Ecology Letters 9, 870649 886.

Weiher, E., Keddy, P., 2001. Assembly Rules: Perspectives, Advances, Retreats. Cambridge University Press, Cambridge.

Winkler, H., Kampichler, C., 2000. Local and regional species richness in communities of surfacedwelling grassland Collembola: indication of species saturation. Ecography 23, 385-392. 
655

656

657

658

659

660

661

662

663

664

665

666

667

668

669

670

671

672

673

674

675

676

677

678

679

680

681

682

\section{Figure captions}

Figure 1. Schematic representation of the experimental design. Soils cores are represented by squares (dark grey for the forest and light grey for the pasture). Letters on squares summarize the treatments: the first letter refers to the origin of the community ("F" for forest and "P" for pasture); the second letter refers to the origin of the soil ("F" for forest and "P" for pasture) and the third letter refers to the habitat (microclimate) in which the core has been transplanted ("F" for forest and "P" for pasture). For species codes see Table 1.

Figure 2. Summary of manipulation steps.

Figure 3. Mean collembolan density in 5 types of controls (experimental, inoculation, natural at the beginning $\left(\mathrm{t}_{0}\right)$ and at the end ( $\left.\mathrm{t}_{\mathrm{end}}\right)$ of the experiment, exclosure) in forest (grey bars) and pasture (white bars) soils (see text for details). Letters indicate significant differences among means. Error bars represent standard errors.

Figure 4. Principal component analysis using abundances of common collembolan species (i.e. present in at least $10 \%$ of the samples) in the 5 types of controls ( 3 manipulation controls e.g. inoculation, exclosure, and experimental controls and 2 natural references e.g. $t_{0}$ and $t_{\text {end }}$ controls). Left: Projection of dataset variability plotted on a factorial map of the first two principal components. Labels on the gravity centers correspond to each treatment. TF0: natural reference in forest at beginning of the experiment, TFend: natural reference in forest at end of the experiment, FFF: control experiment for forest community, TeF: inoculation control for forest community in forest soil, TexF: fauna removal control for forest community, TP0: natural reference in pasture at beginning of the experiment, TPend: natural reference in pasture at end of the experiment, PPP: control experiment for pasture community, TeP: inoculation control for pasture community in pasture soil, TexP: fauna removal control for pasture community. Right: Correlation circle plot with species vectors (vector labels correspond to species codes in Table 1).

Figure 5. Mean soil pH (a) and mean soil moisture (b) in experimental forest (left) and pasture (right) soil cores, placed in forest (grey bars) and pasture (white bars) microclimates and in natural references (dashed bars). Letters indicate significant differences among means. Error bars represent standard errors. 
683 Figure 6: Mean collembolan abundance (a), species richness (b) and Shannon index (c) in 684 experimental soil cores. From the left to right: forest community in forest soil, forest community in 685 pasture soil, pasture community in forest soil, and pasture community in pasture soil. Grey bars: forest 686 microclimate and white bars: pasture microclimate. Letters indicate significant differences among 687 means. Error bars represent standard errors.

688 Figure 7: Between-group analysis on the abundance of common species, with the composite factor 689 COM/S/CLIM as explanatory variable. Left: Projection of dataset variability plotted on a factorial map 690 of the first two discriminating axes according to a combination of COM, S and CLIM. Labels on the 691 gravity centers correspond to each treatment (treatment codes according to Fig. 1). Right: Correlation 692 circle plot with species vectors (vector labels correspond to species codes in Table 1). Eigen values $6930.44,0.24,0.16$ for axes 1 to 3, respectively; Randtest: simulated p-value: 0.001; Explained variance: 6940.56.

695 Figure 8: Abundance of six species in the experimental treatments. (a) Isotomiella minor (Group A); 696 (b) Detriturus jubilarius (Group B); (c) Protaphorura armata (Group C); (d) Mesaphorura 697 macrochaeta (Group D); (e) Isotoma viridis (Group E); (f) Xenylla tullbergi (Group E); Upper right: 698 correlation circle of the between-group analysis (Fig. 7). For group codes see Table1. Letters on bars 699 indicate significant differences among means. Labels under bars correspond to each treatment (for treatment codes see Fig. 1). Error bars represent standard errors. 
702

703

704

705

706

707

708

709

710

711

712

713

714

715

716

Table 1. Presence/absence in inoculation and exclosure controls of the 16 species which were common in experimental soil cores $(\mathrm{X}=$ not present in controls; $\mathrm{F}=$ present in forest control only; $\mathrm{P}=$ present in pasture control only; FP = present in both forest and pasture controls). Results of generalized linear models testing the effect of three factors (community origin, soil nature and microclimate) on each species abundance $(*=\mathrm{p}<0.05 ; * *=\mathrm{p}<0.01 ; * * *=\mathrm{p}<0.001$; / = not significant; $\mathrm{F}=$ species more abundant in forest community, soil or microclimate; $\mathrm{P}=$ species more abundant in pasture community, soil or microclimate). Habitat preference was calculated using IndVal index with the data set produced in Ponge et al. (2003): $g$ = generalist species; $\mathrm{f}$ = strict-forest species; $\mathrm{fp}$ = forest-preferring species; a = strict agricultural species; ap = agricultural-preferring species.

Response groups correspond to the six groups formed using species responses to the three factors community origin, soil, and microclimate. Group A = true forest species; Group B = forest species preferring pasture soil; Group C = pasture species preferring forest soil; Group D = pasture species preferring forest microclimate; Group E = species preferring pasture microclimate; Group F = pasture species.

\begin{tabular}{lllllllll}
\hline & $\begin{array}{l}\text { Species } \\
\text { codes }\end{array}$ & Exclosure & Inoculation & Community & Soil & Microclimate & $\begin{array}{l}\text { Habitat } \\
\text { preference }\end{array}$ & $\begin{array}{l}\text { Response } \\
\text { group }\end{array}$ \\
\hline Isotomiella minor & Iso.min & $\mathrm{X}$ & $\mathrm{F}$ & $\mathrm{F} * * *$ & $\mathrm{~F} * * *$ & $\mathrm{~F} * * *$ & $\mathrm{fp}$ & $\mathrm{A}$ \\
Megalothorax minimus & Meg.min & $\mathrm{X}$ & $\mathrm{F}$ & $\mathrm{F} * * *$ & $\mathrm{~F} * *$ & $\mathrm{~F} * * *$ & $\mathrm{fp}$ & $\mathrm{A}$ \\
Pseudosinella mauli & Pse.mau & $\mathrm{X}$ & $\mathrm{F}$ & $\mathrm{F} * * *$ & $\mathrm{~F} * *$ & $/$ & $\mathrm{f}$ & $\mathrm{A}$ \\
Folsomia quadrioculata/manolachei & Fol & $\mathrm{X}$ & $\mathrm{FP}$ & $\mathrm{F} * * *$ & $\mathrm{P} * * *$ & $\mathrm{~F} * * *$ & $\mathrm{~g}$ & $\mathrm{~B}$ \\
Friesea truncata & Fri.tru & $\mathrm{X}$ & $\mathrm{F}$ & $\mathrm{F} * * *$ & $\mathrm{P} * *$ & $\mathrm{~F} * *$ & $\mathrm{fp}$ & $\mathrm{B}$ \\
Detriturus jubilarius & Det.jub & $\mathrm{X}$ & $\mathrm{F}$ & $\mathrm{F} * * *$ & $\mathrm{P} * * *$ & $\mathrm{~F} * * *$ & $\mathrm{f}$ & $\mathrm{B}$ \\
Protaphorura armata & Pro.arm & $\mathrm{P}$ & $\mathrm{P}$ & $\mathrm{P} * * *$ & $\mathrm{~F} *$ & $\mathrm{~F} * * *$ & ap & $\mathrm{C}$ \\
Pseudosinella alba & Pse.alb & $\mathrm{X}$ & $\mathrm{X}$ & $\mathrm{P} * * *$ & $\mathrm{~F} * * *$ & & $\mathrm{a}$ & $\mathrm{C}$ \\
Mesaphorura macrochaeta & Mes.mac & $\mathrm{FP}$ & $\mathrm{FP}$ & $\mathrm{P} * * *$ & $\mathrm{P} * * *$ & $\mathrm{~F} * * *$ & $\mathrm{~g}$ & $\mathrm{D}$ \\
Parisotoma notabilis & Par.not & $\mathrm{FP}$ & $\mathrm{FP}$ & $\mathrm{P} * * *$ & $\mathrm{P} * * *$ & $\mathrm{~F} * * *$ & ap & $\mathrm{D}$ \\
Brachystomella parvula & Bra.par & $\mathrm{P}$ & $\mathrm{X}$ & $\mathrm{F} * * *$ & $\mathrm{~F} * *$ & $\mathrm{P} * * *$ & ap & $\mathrm{E}$ \\
Lepidocyrtus lanuginosus & Lep.lan & $\mathrm{FP}$ & $\mathrm{FP}$ & $/$ & $\mathrm{F} *$ & $\mathrm{P} *$ & $\mathrm{~g}$ & $\mathrm{E}$ \\
Sphaeridia pumilis & Sph.Pum & $\mathrm{FP}$ & $\mathrm{F}$ & $\mathrm{F} *$ & $/$ & $\mathrm{P} *$ & ap & $\mathrm{E}$ \\
Xenylla tullbergi & Xen.tul & $\mathrm{F}$ & $\mathrm{F}$ & $\mathrm{F} * * *$ & $\mathrm{P} * * *$ & $\mathrm{P} * * *$ & $\mathrm{f}$ & $\mathrm{F}$ \\
Isotoma viridis & Iso.vir & $\mathrm{P}$ & $\mathrm{P}$ & $/$ & $\mathrm{P} * * *$ & $\mathrm{P} * * *$ & ap & $\mathrm{F}$ \\
Sminthurides schoetti & Smi.sch & $\mathrm{P}$ & $\mathrm{X}$ & $/$ & $\mathrm{P} * * *$ & $\mathrm{P} * *$ & ap & $\mathrm{F}$ \\
\hline
\end{tabular}


718 Table 2. Effect of soil nature and microclimate (and interaction between both factors) on total carbon

719 (Ctot) and nitrogen (Ntot) content, soil pH and soil moisture of experimental soil cores. Results of

720 linear and generalized linear models (F value/Chi square and degrees of freedom df). Significance

721 levels: $* *=\mathrm{p}<0.01 ; * * *=\mathrm{p}<0.001 ; \mathrm{NS}=$ not significant.

722

$\mathrm{F}$ values/Chi square

\begin{tabular}{|c|c|c|c|c|c|c|c|}
\hline & \\
\hline & df & Ctot & $\mathrm{pH}$ & & Moist & & Ntot \\
\hline Soil (S) & 1 & $48.7 * * *$ & 30.49 & *** & 105.2 & $* * *$ & $1.52 \mathrm{NS}$ \\
\hline Climate (Cli) & 1 & 0.14 NS & 20.35 & *** & 9.56 & $* *$ & $0.3 \quad$ NS \\
\hline S : Cli & 1 & $0.07 \mathrm{NS}$ & 2.4 & NS & 0.03 & NS & $0.36 \mathrm{NS}$ \\
\hline $\begin{array}{l}\text { model type } \\
\text { transformation }\end{array}$ & & $\begin{array}{l}\text { Normal } \\
\log _{10}\end{array}$ & $\begin{array}{l}\text { Gamn } \\
\text { none }\end{array}$ & & $\begin{array}{l}\text { Norm } \\
\log _{10}\end{array}$ & & $\begin{array}{l}\text { Normal } \\
\log _{10}\end{array}$ \\
\hline
\end{tabular}

723

724

725 
726 Table 3. Effect of community origin, soil nature and microclimate on total abundance, species

727 richness and Shannon index. Results of linear models (F values and degrees of freedom df) tested after

728 a procedure of automatic selection based on AIC criterion. NT $=$ not tested. $*=p<0.05 ; * *=p<$

$7290.01 ; * * *=\mathrm{p}<0.001 ; \mathrm{NS}=$ not significant.

\begin{tabular}{|c|c|c|c|c|c|c|c|c|c|}
\hline \multirow[b]{3}{*}{ Community (Co) } & \multicolumn{3}{|c|}{ F values } & \multirow[b]{2}{*}{$\mathrm{df}$} & \multirow{2}{*}{\multicolumn{2}{|c|}{ Species richness }} & \multirow{3}{*}{$\begin{array}{l}\mathrm{df} \\
1\end{array}$} & \multirow{2}{*}{\multicolumn{2}{|c|}{ Shannon index }} \\
\hline & $\mathrm{df}$ & Abund & lance & & & & & & \\
\hline & 1 & 10.98 & $* *$ & 1 & 15.8 & $* * *$ & & 33.85 & $* * *$ \\
\hline Soil (S) & 1 & 5.29 & $*$ & 1 & 1.9 & NS & 1 & 9.33 & $* *$ \\
\hline Climate (Cli) & 1 & 50.02 & $* * *$ & 1 & 0.06 & NS & 1 & 0.88 & NS \\
\hline Co : S & NT & & & 1 & 0.8 & NS & NT & & \\
\hline Co : Cli & NT & & & 1 & 0.007 & NS & 1 & 11.04 & $* *$ \\
\hline S : Cli & NT & & & 1 & 0.007 & NS & NT & & \\
\hline Co : S : Cli & NT & & & 1 & 0.16 & NS & NT & & \\
\hline $\begin{array}{l}\text { model type } \\
\text { transformation }\end{array}$ & & $\begin{array}{l}\text { Norma } \\
\log _{10}\end{array}$ & & & $\begin{array}{l}\text { Norme } \\
\text { none }\end{array}$ & & $\begin{array}{l}\text { No } \\
\text { nor }\end{array}$ & & \\
\hline
\end{tabular}

730

731

732 


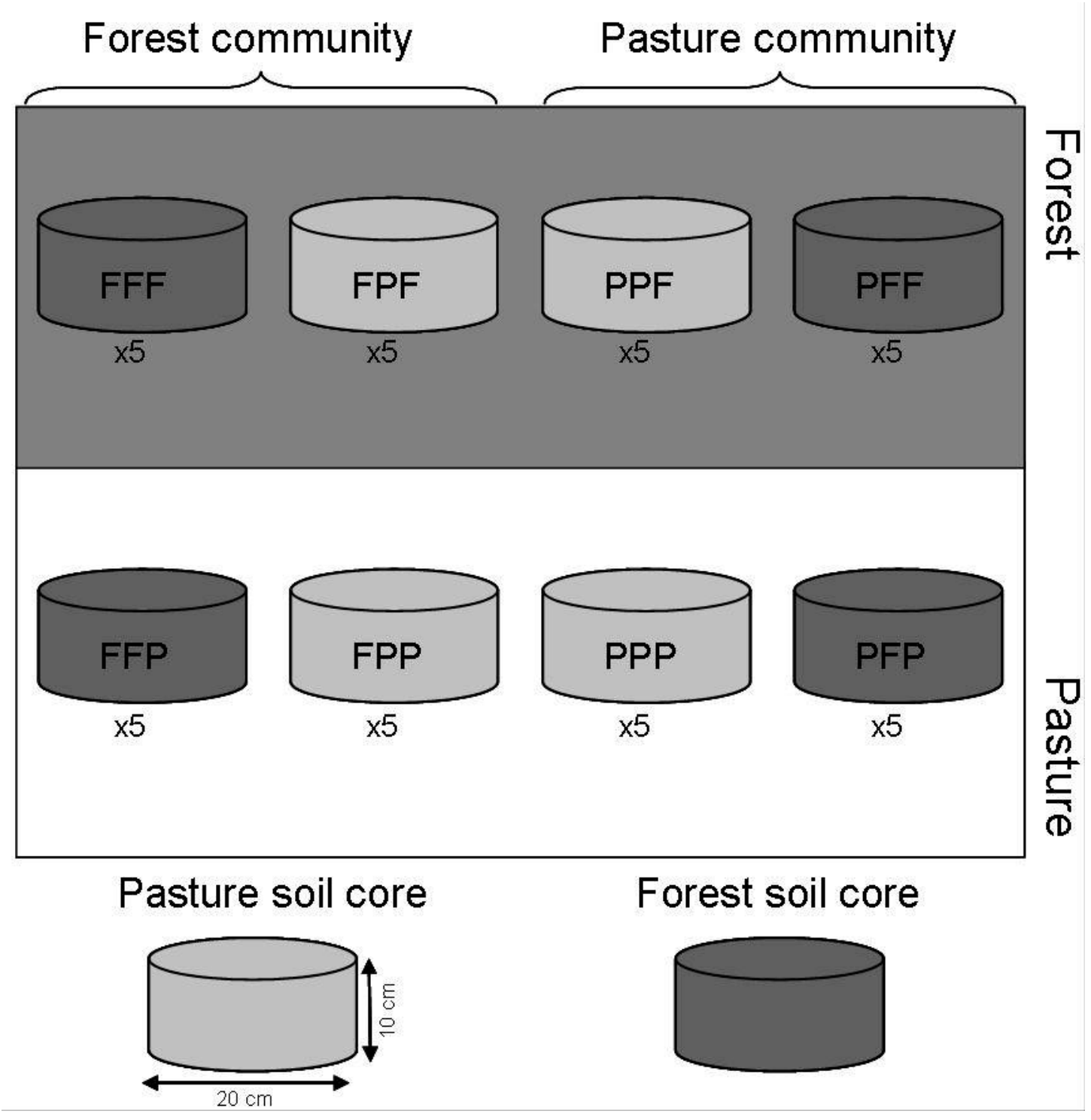

$735 \quad$ Fig. 1 


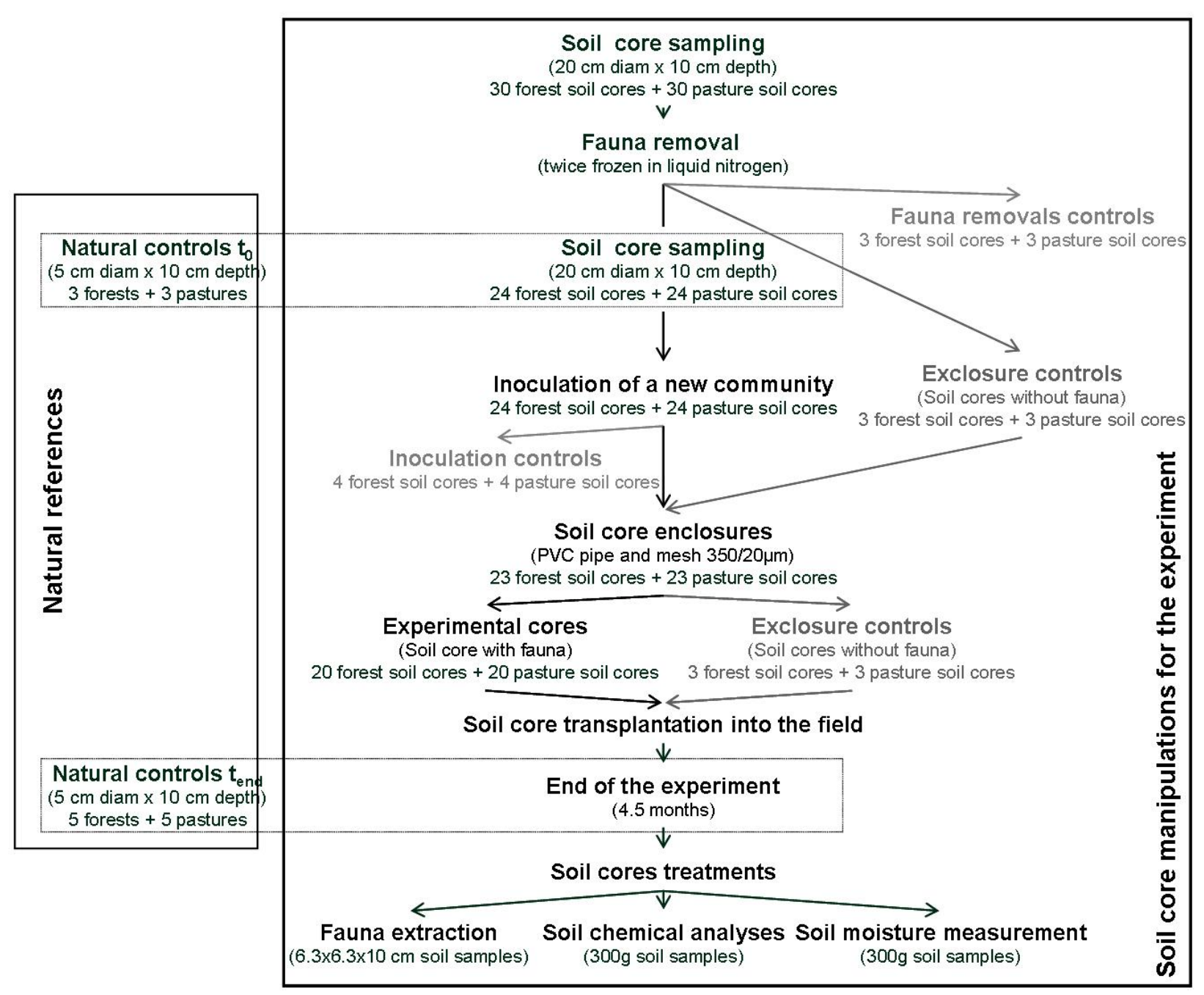




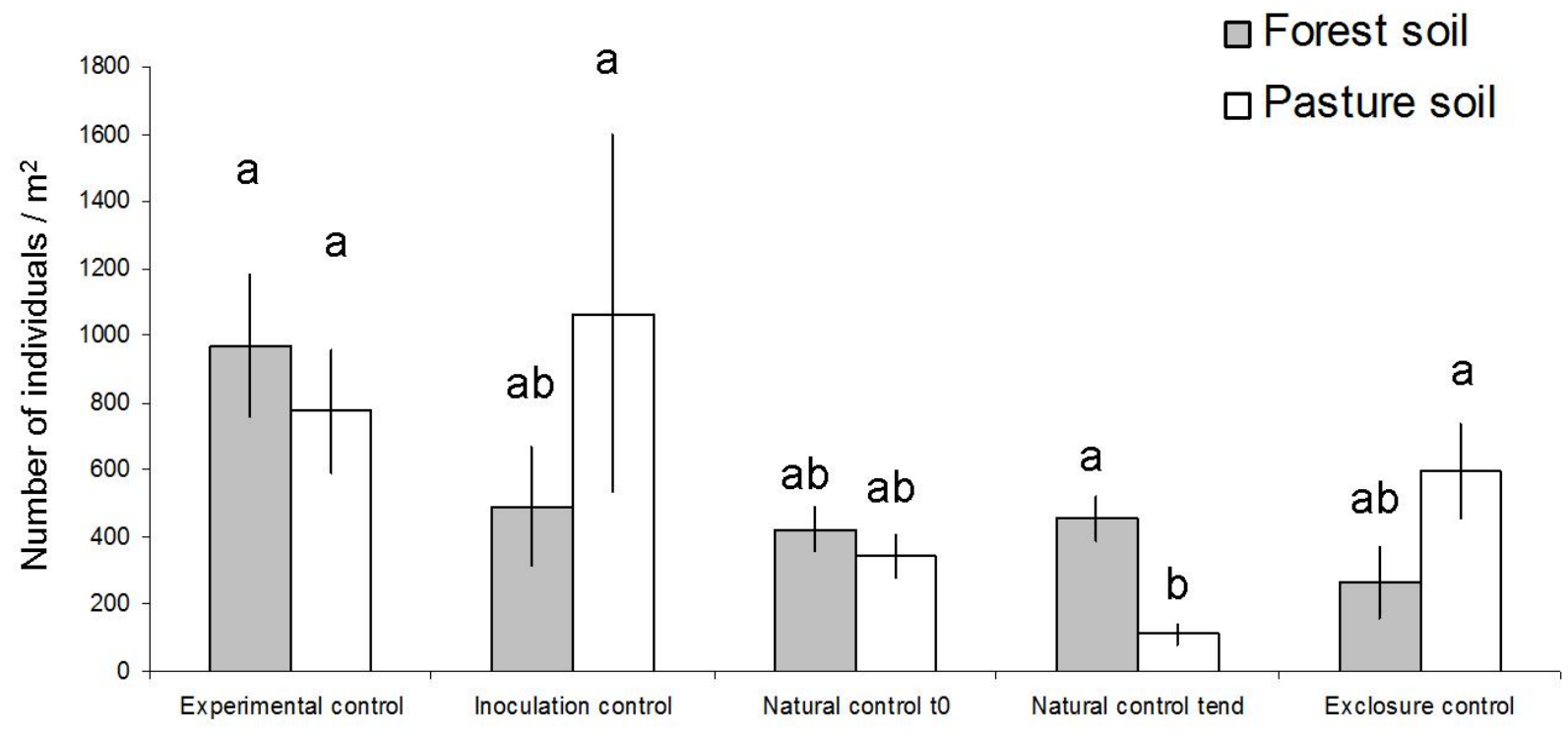

$741 \quad$ Fig. 3 


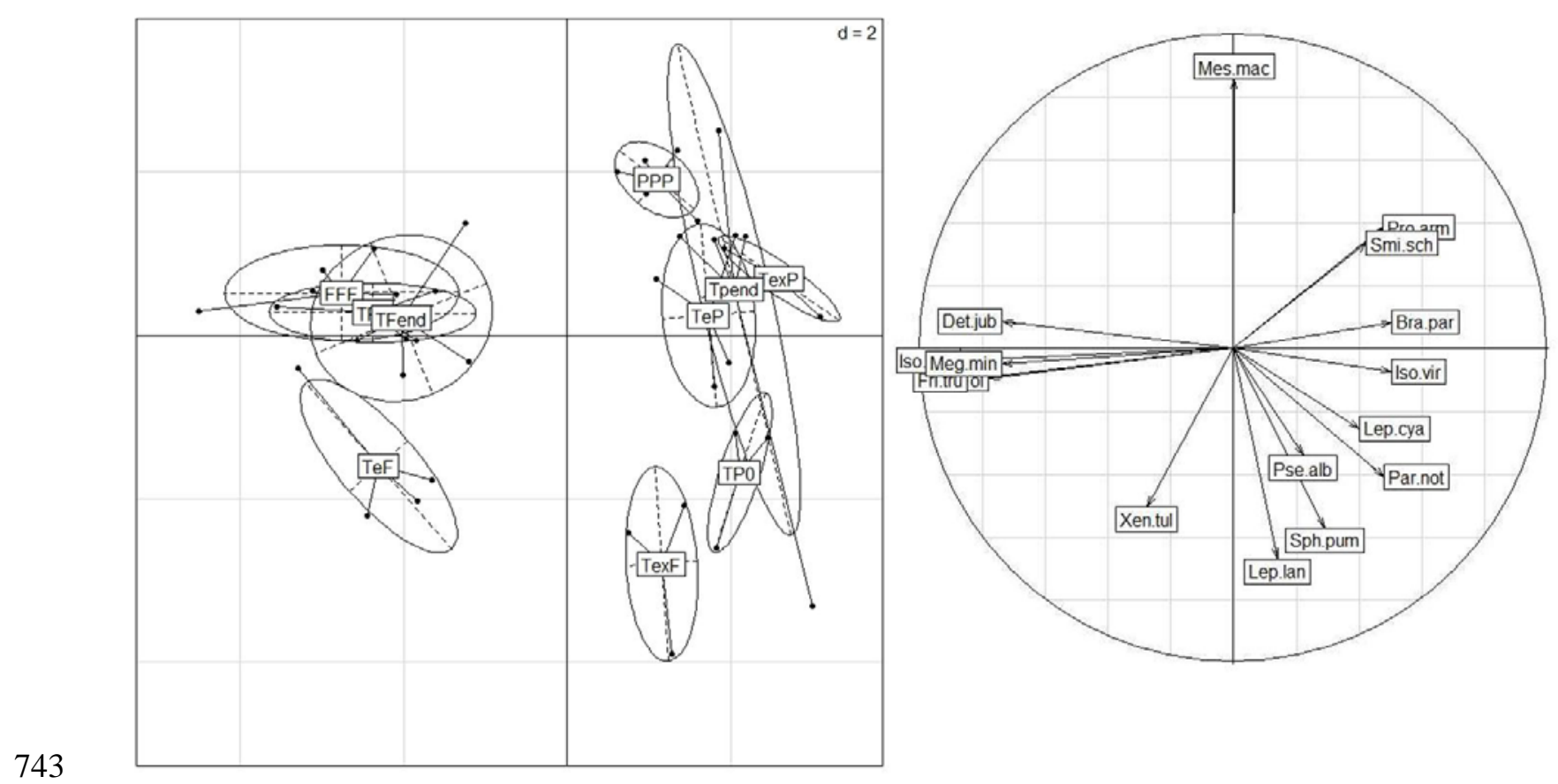

$744 \quad$ Fig. 4

745 
a)

$\square$ Forest microclimate

$\square$ Pasture microclimate

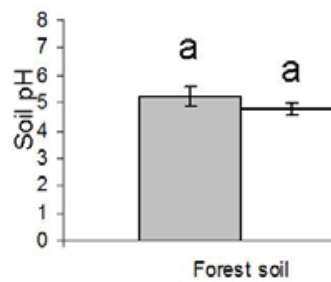

b

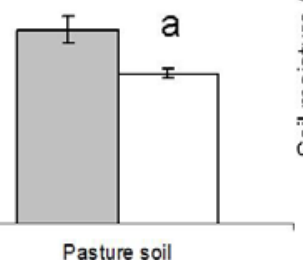

a

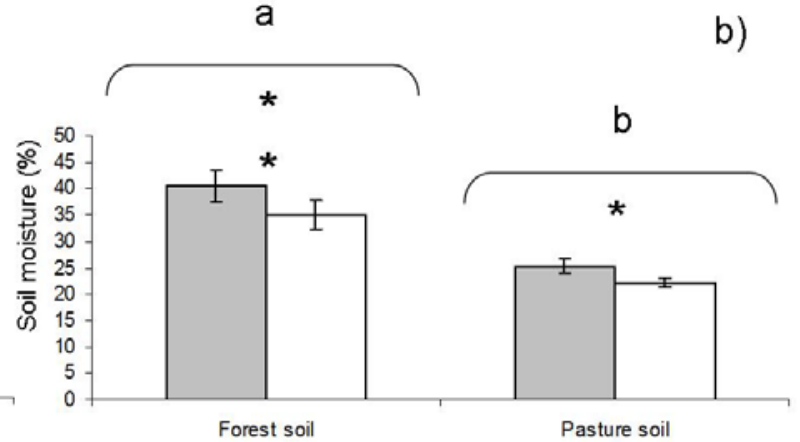

Pasture soil

b)

Fig. 5 

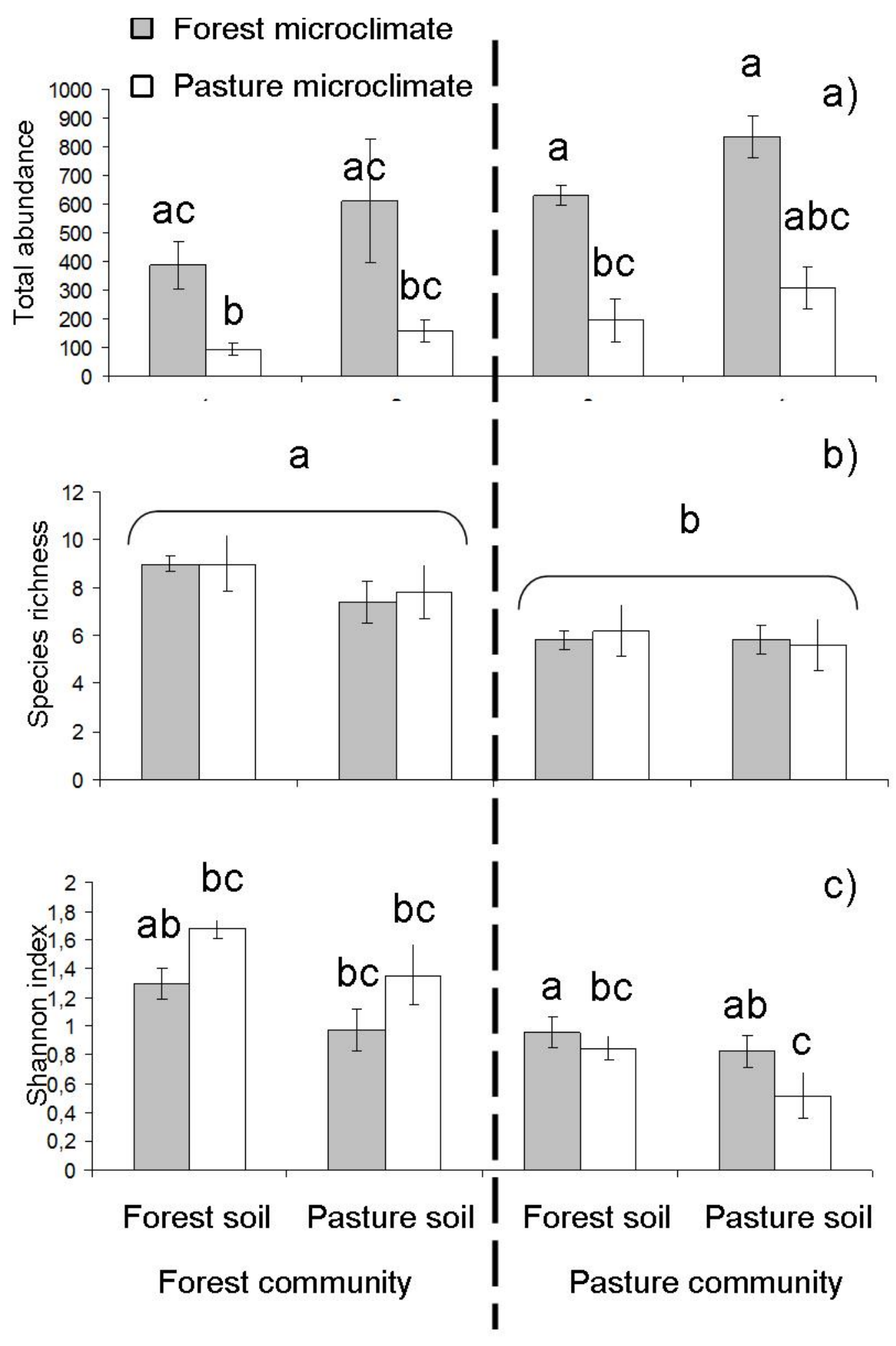

Fig. 6 

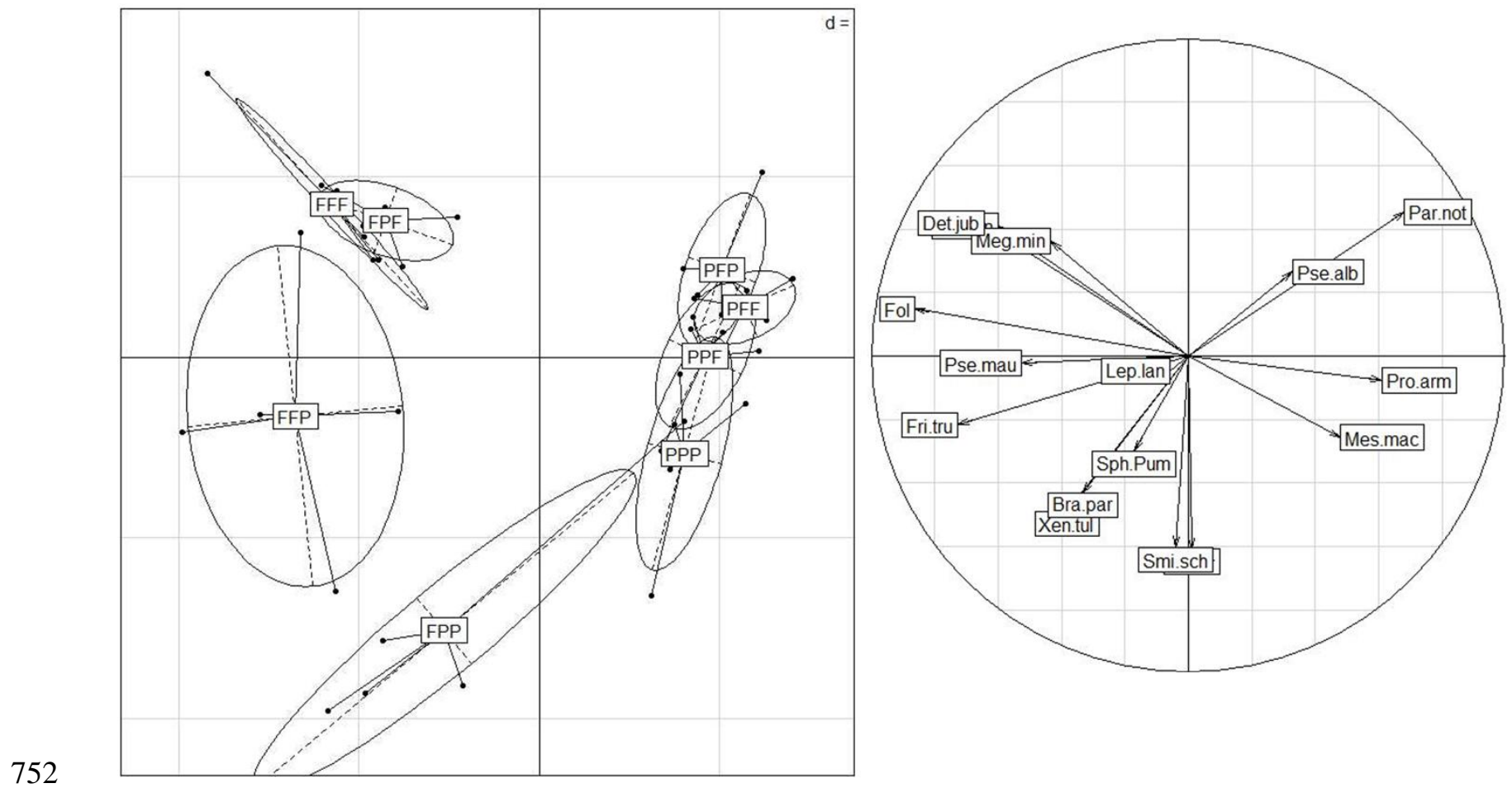

$753 \quad$ Fig. 7

754 
a) Isotomiella minor

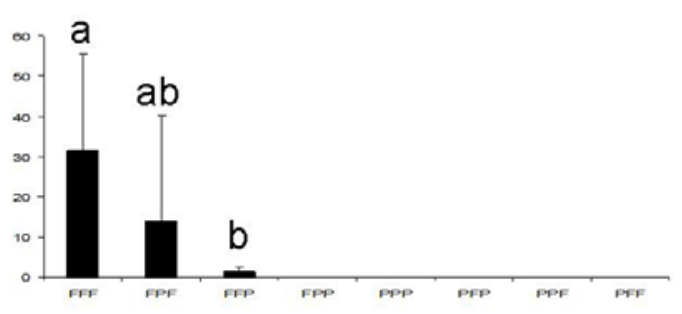

c) Protaphorura armata

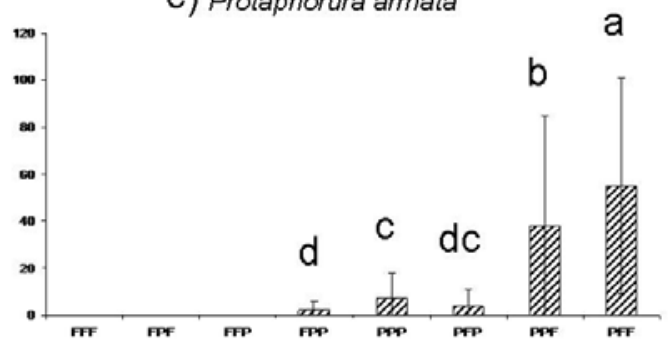

e) Isotoma viridis

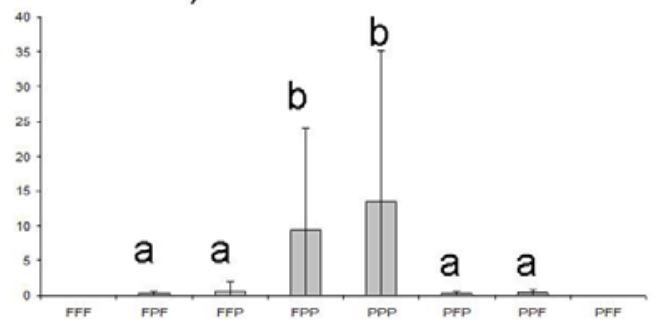

b) Detriturus jubilarius

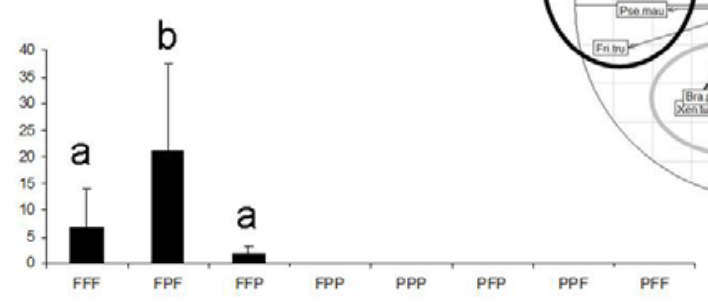

d) Mesaphorura macrochaeta

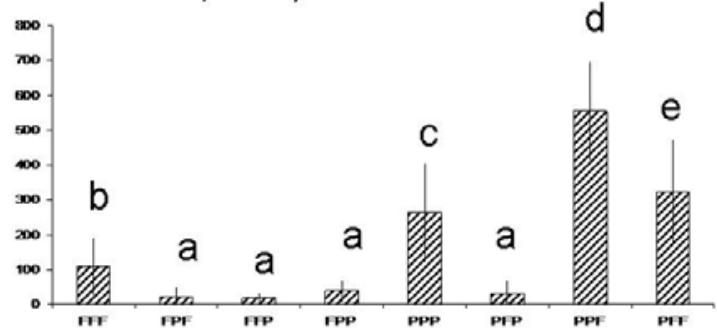

f) Xenylla tullbergi

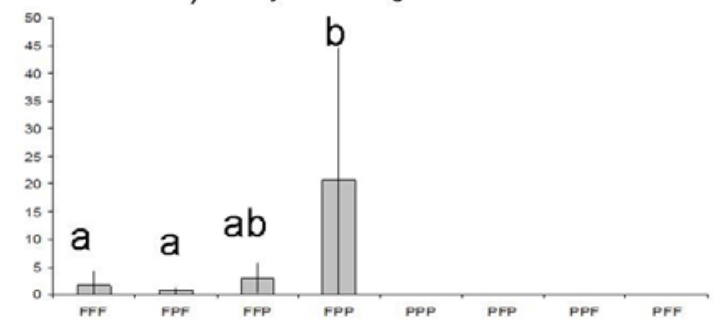

Fig. 8 
758 Appendix. Abundances of the 16 common species in the eight experimental treatments together with

759 the correlation circle of between-group analysis performed on the abundances of the 16 common

760 species using a combination of community origin, soil, and microclimate as explanatory variable.

761 Letters on bars indicate significant differences. Labels under bars correspond to each treatment (codes 762 according to Figure 1).

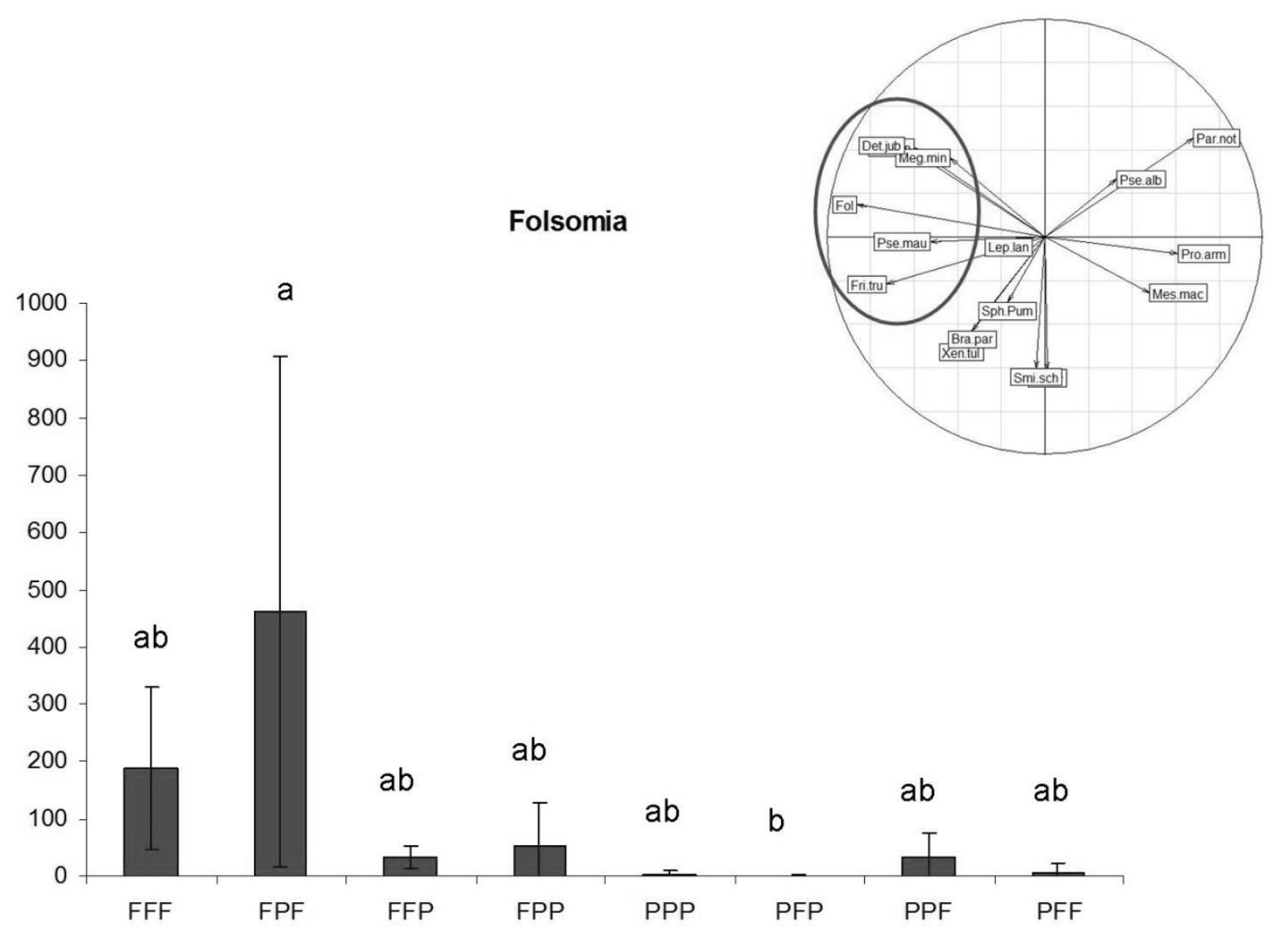


Friesea truncata

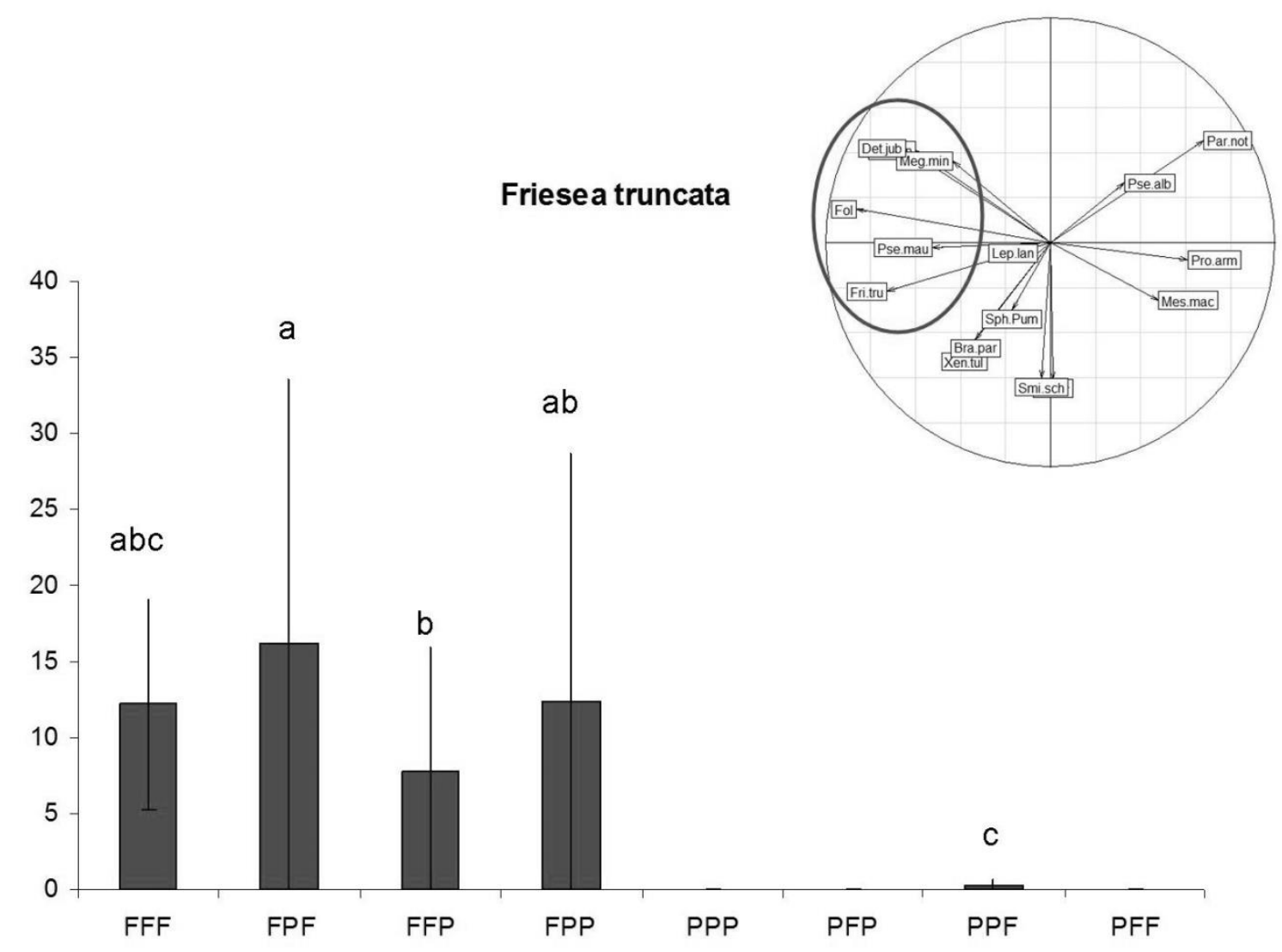

764
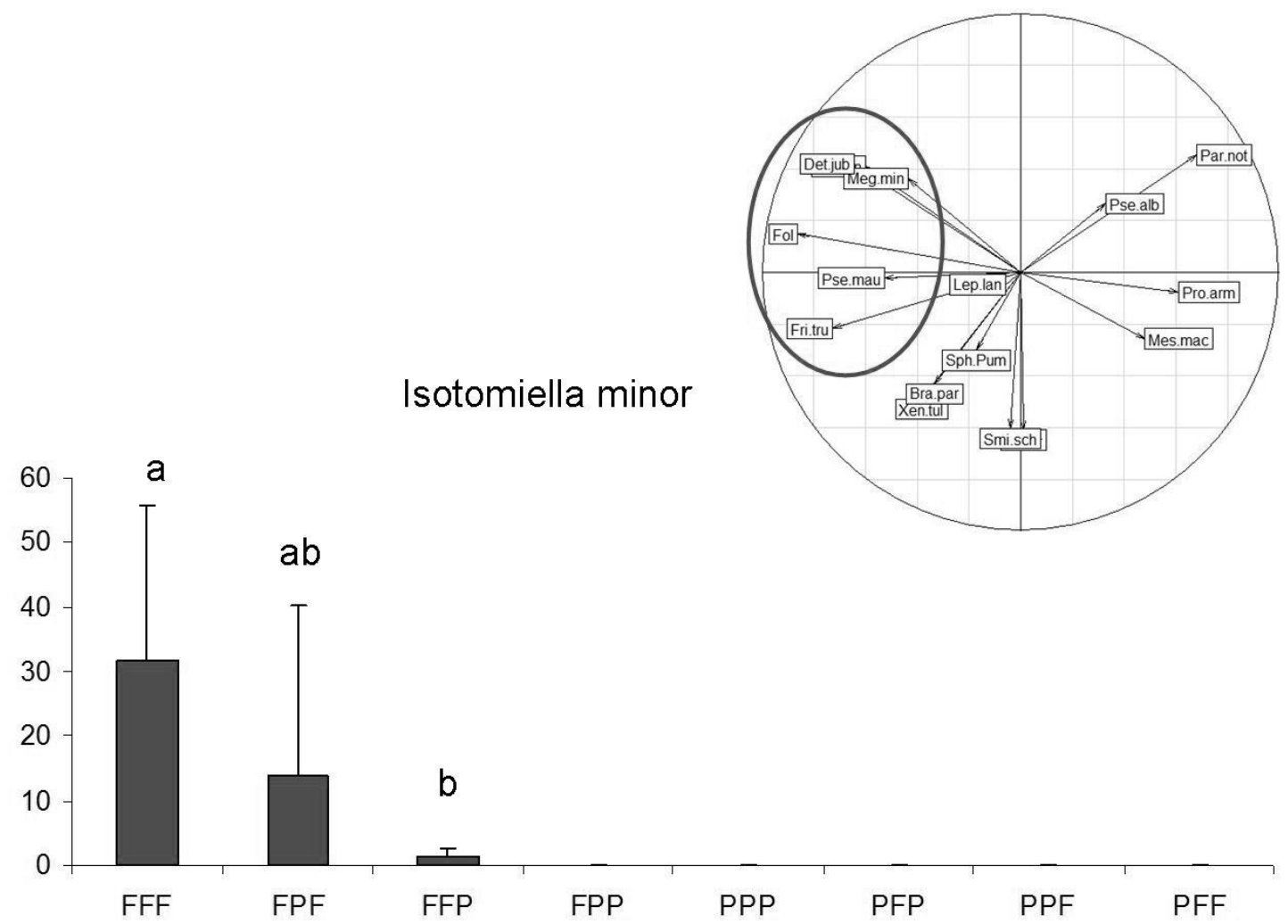
b
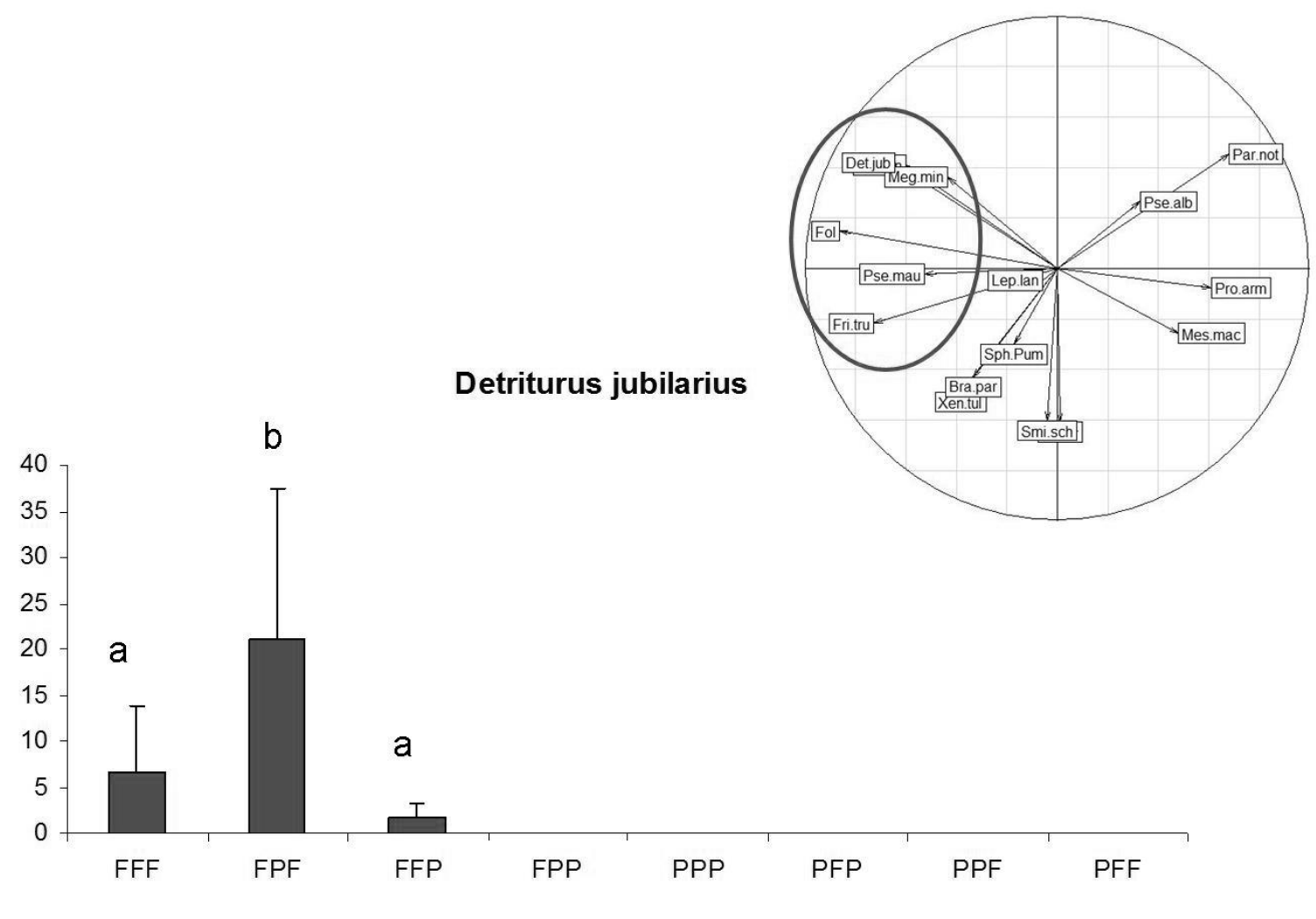

Megalothorax minimus

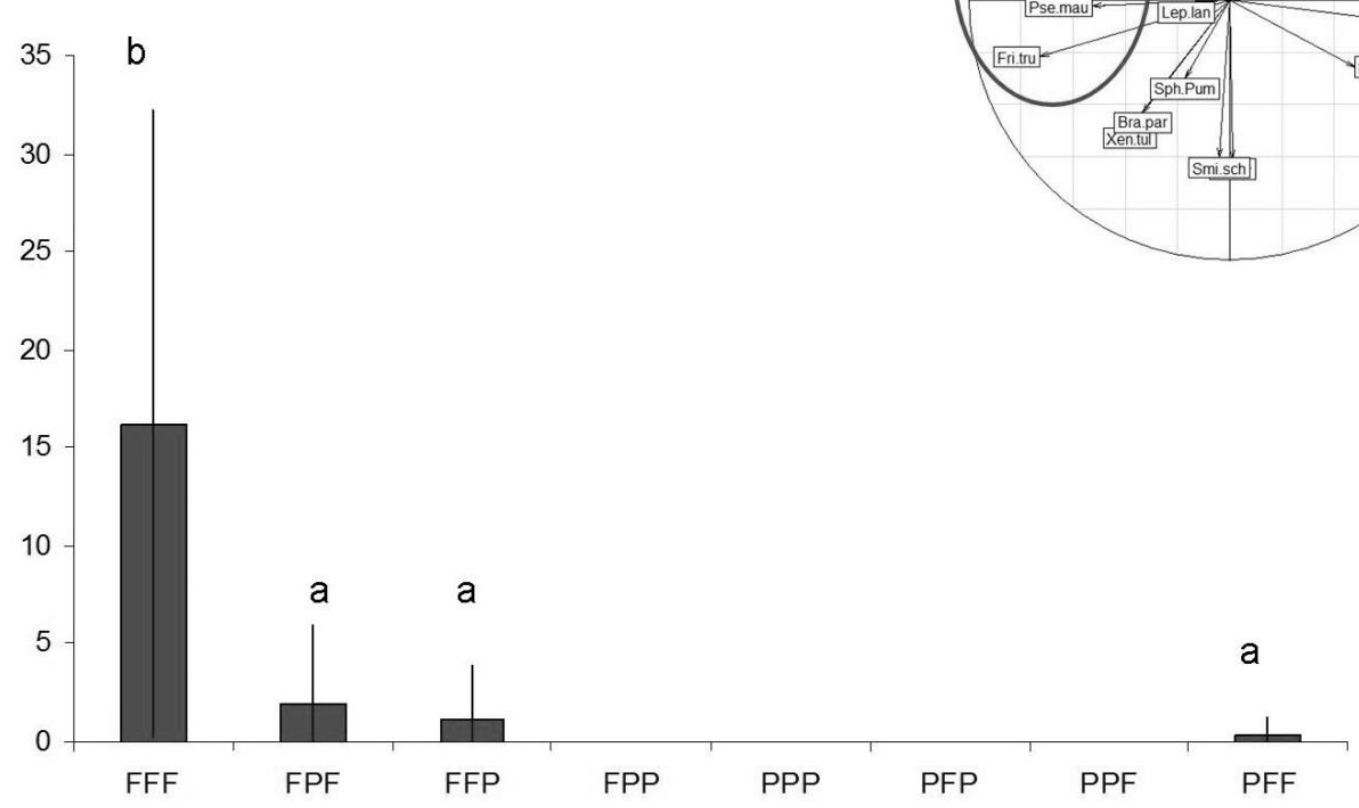



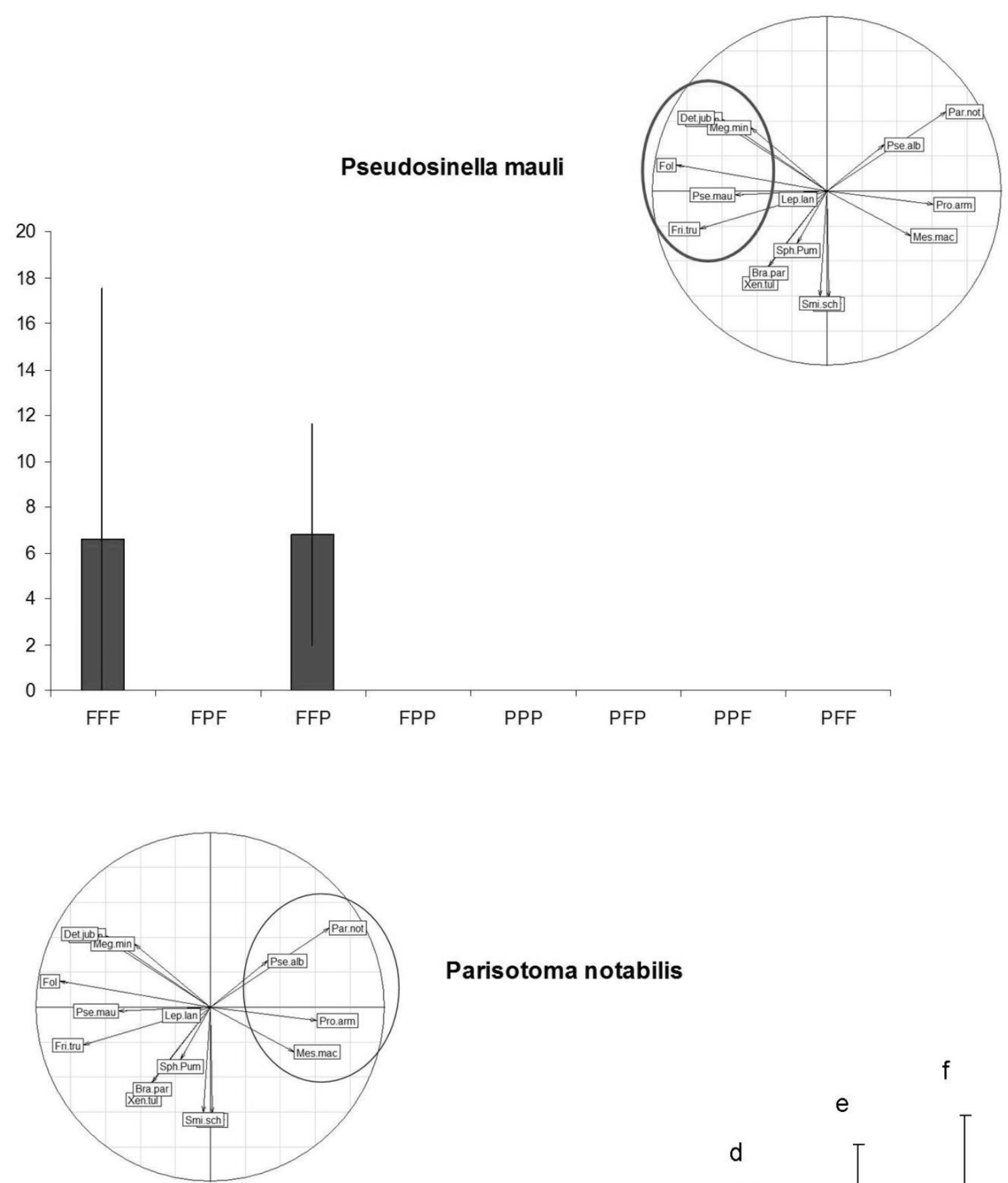

Parisotoma notabilis

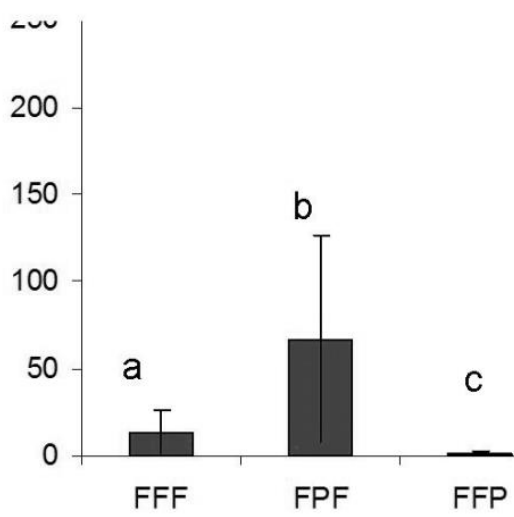




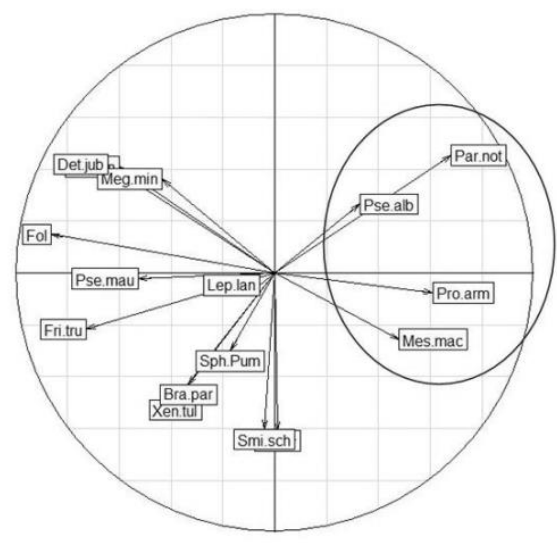

\section{Protaphorura armata}
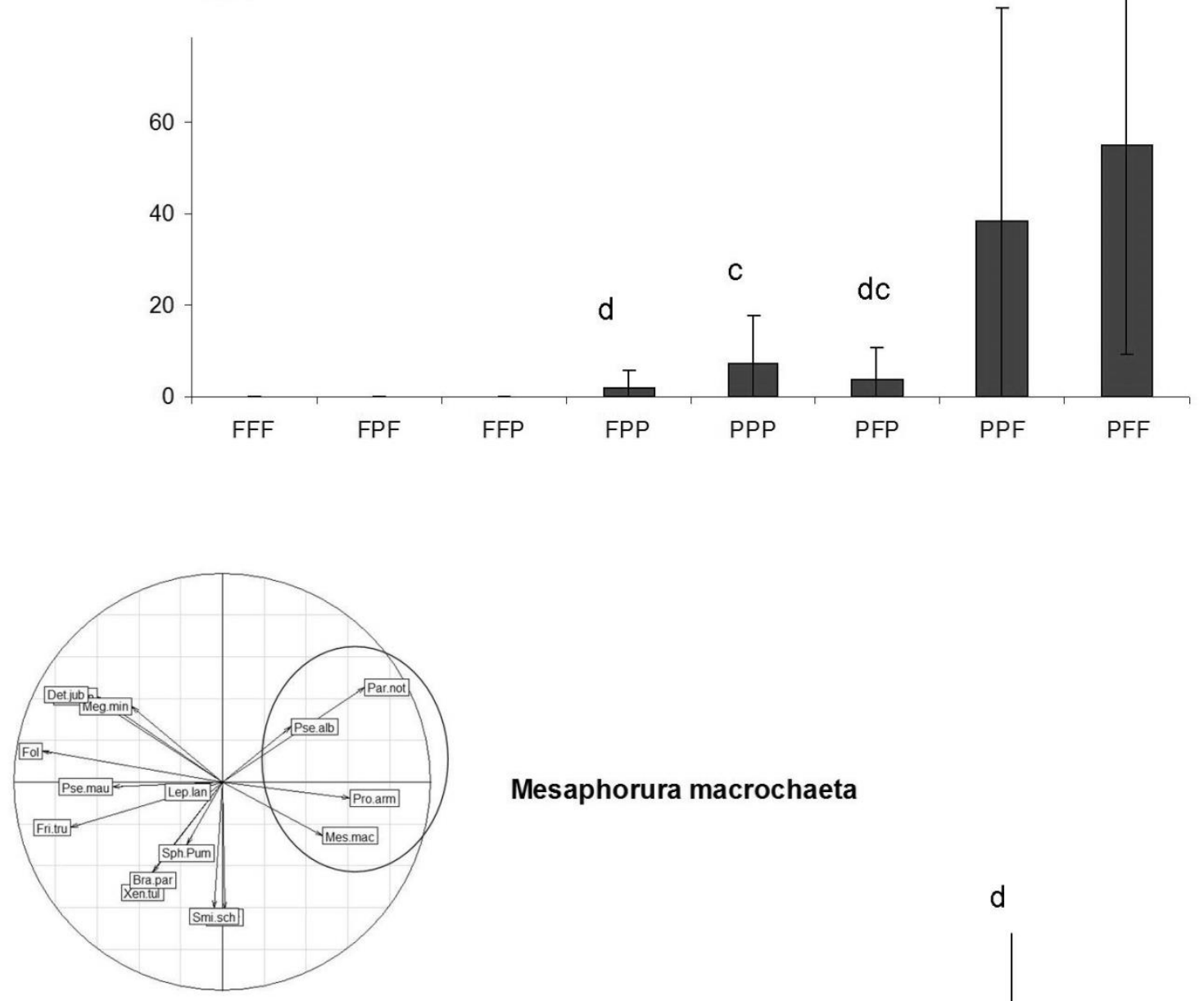

Mesaphorura macrochaeta

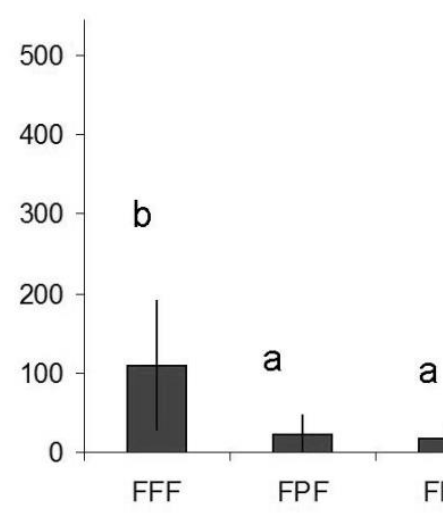




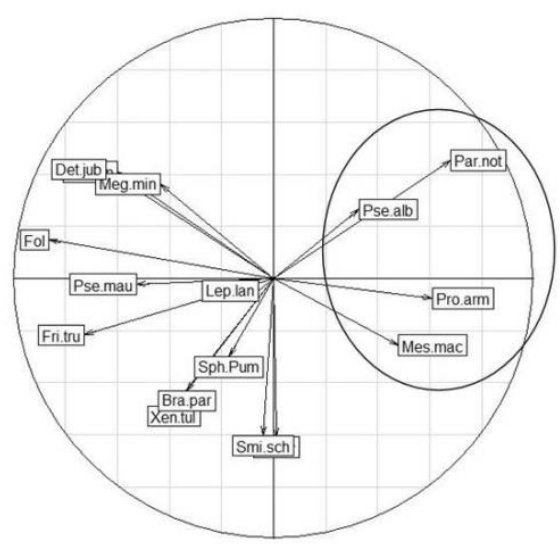

Pseudosinella alba
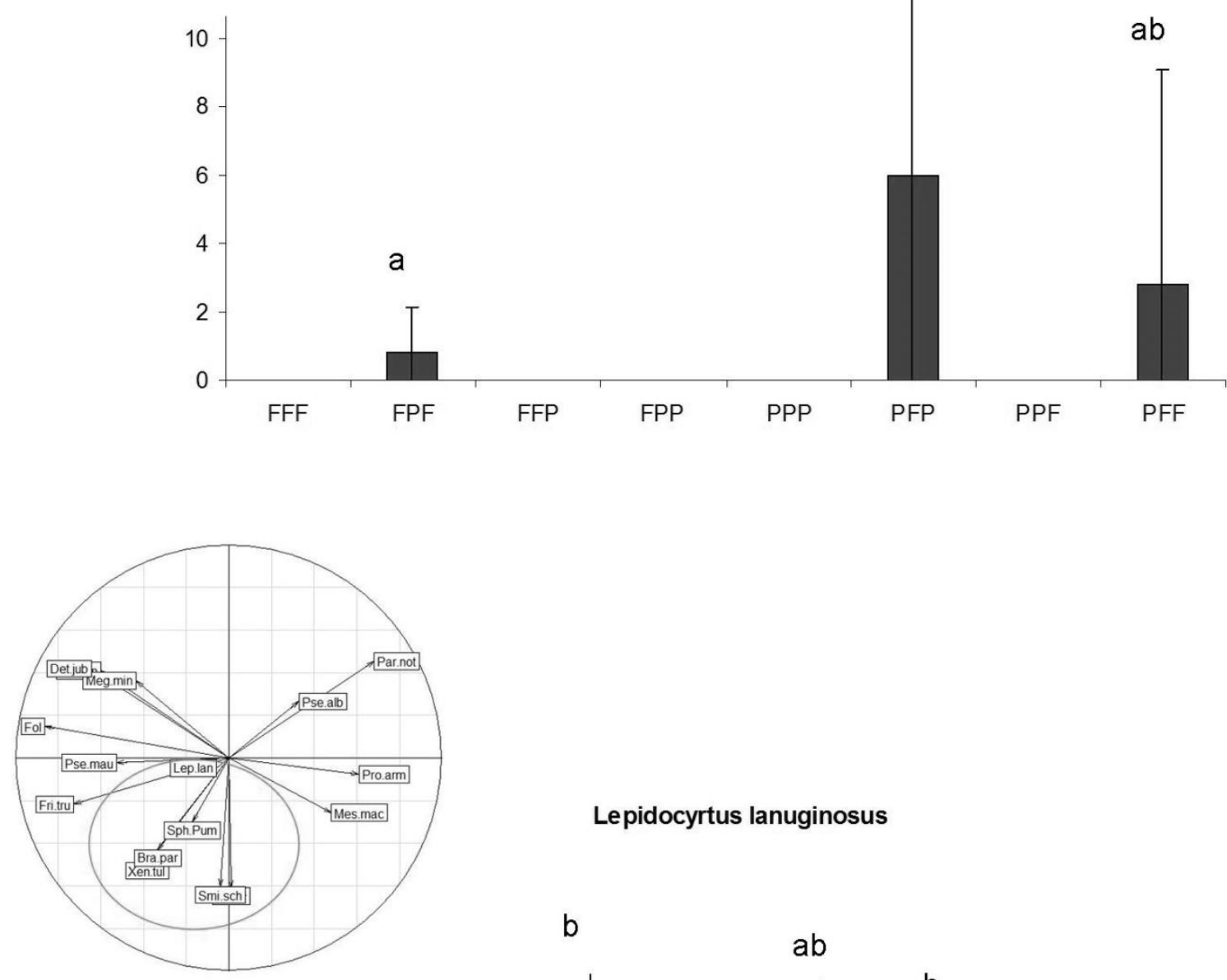

Lepidocyrtus lanuginosus

b

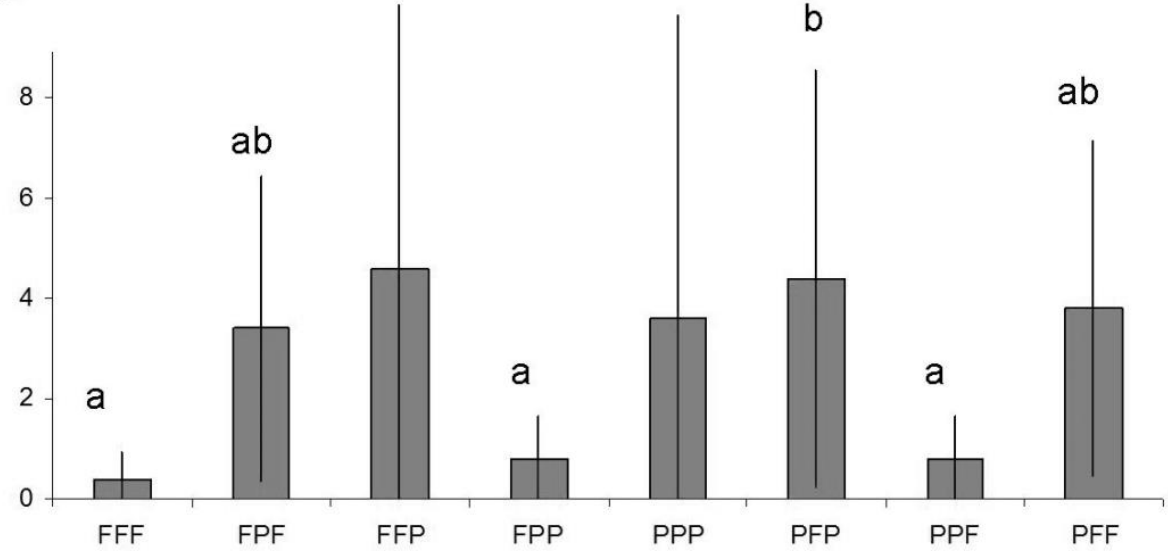


Sphaeridia pumilis

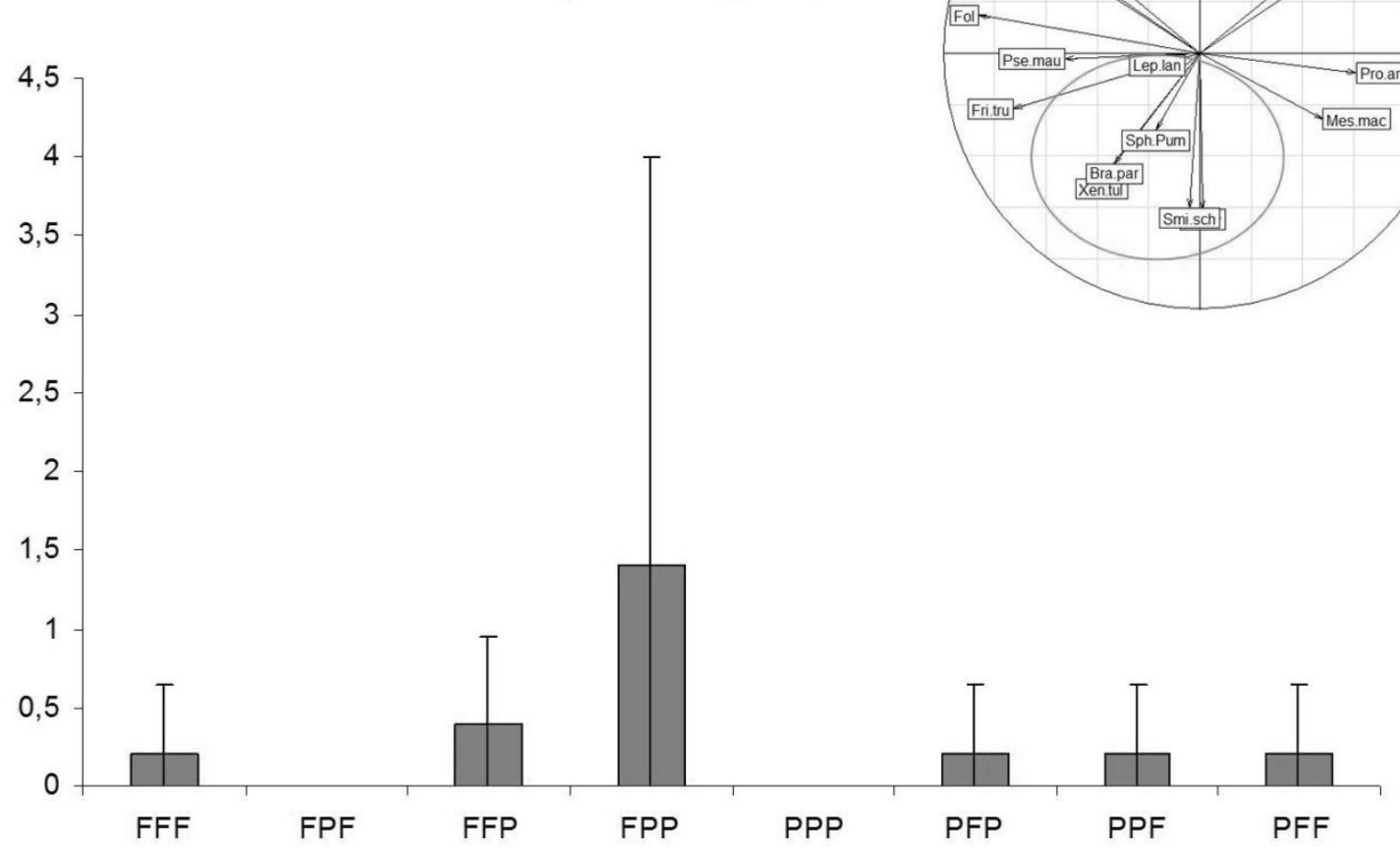

Xenylla tullbergi

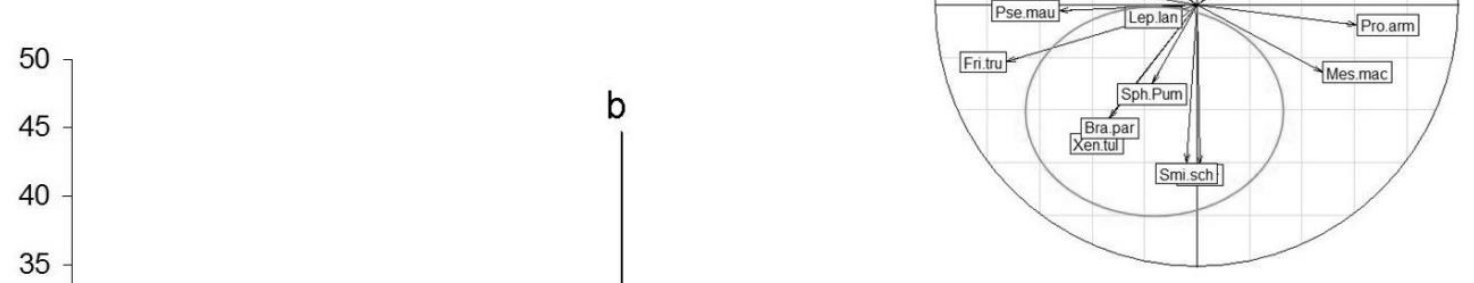




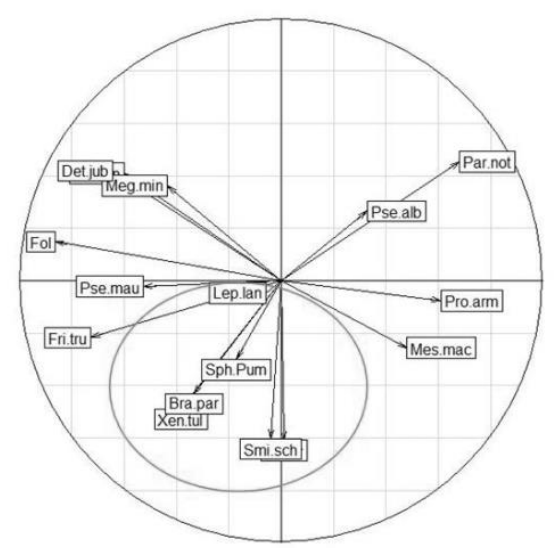

Sminthurides schoetti

776

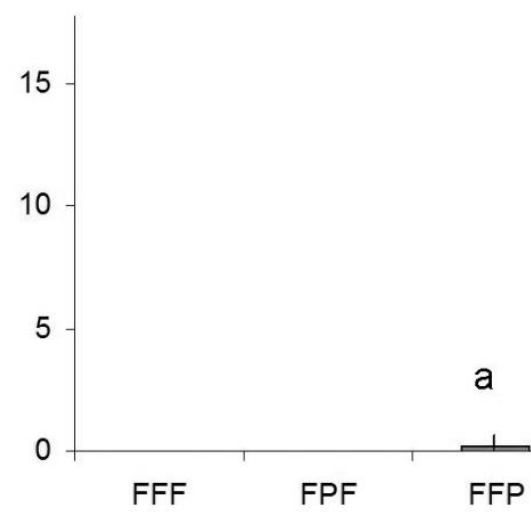

b

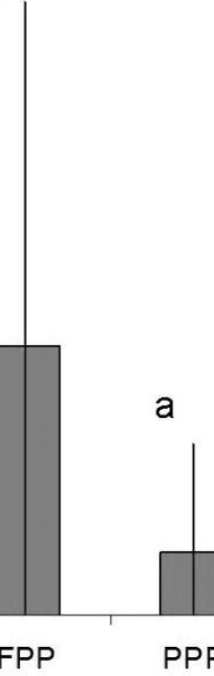

b

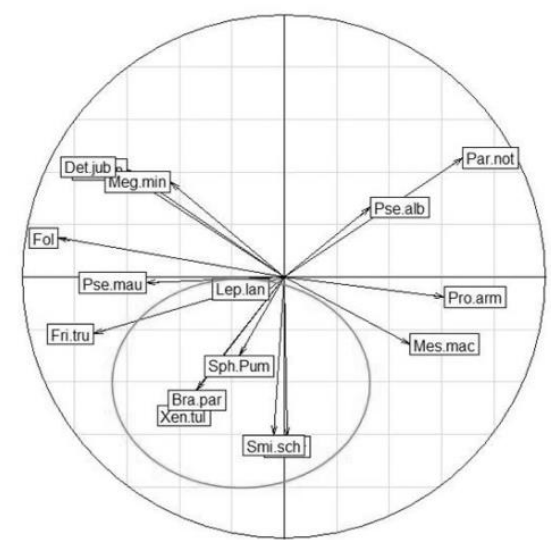

a

25

a

Brachystomella parvula

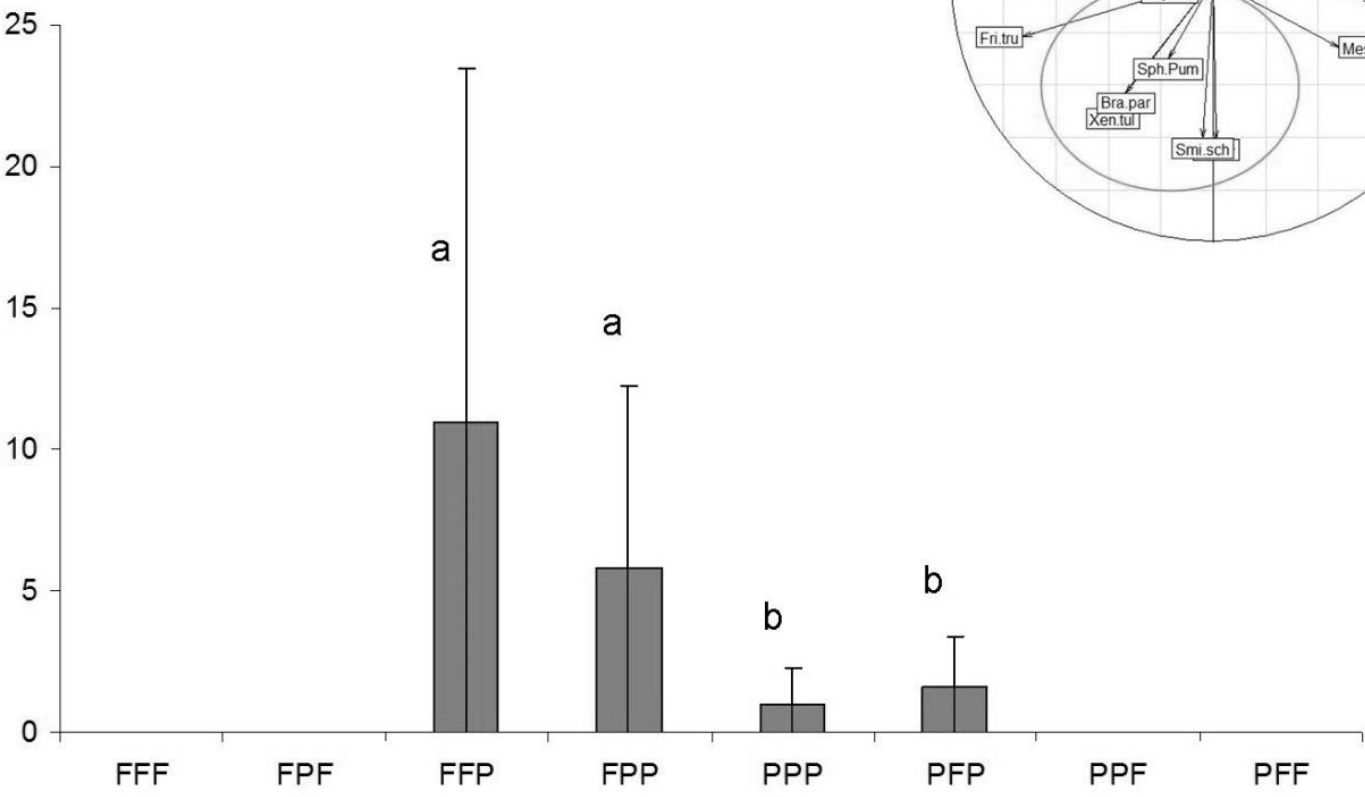




\section{Isotoma viridis}

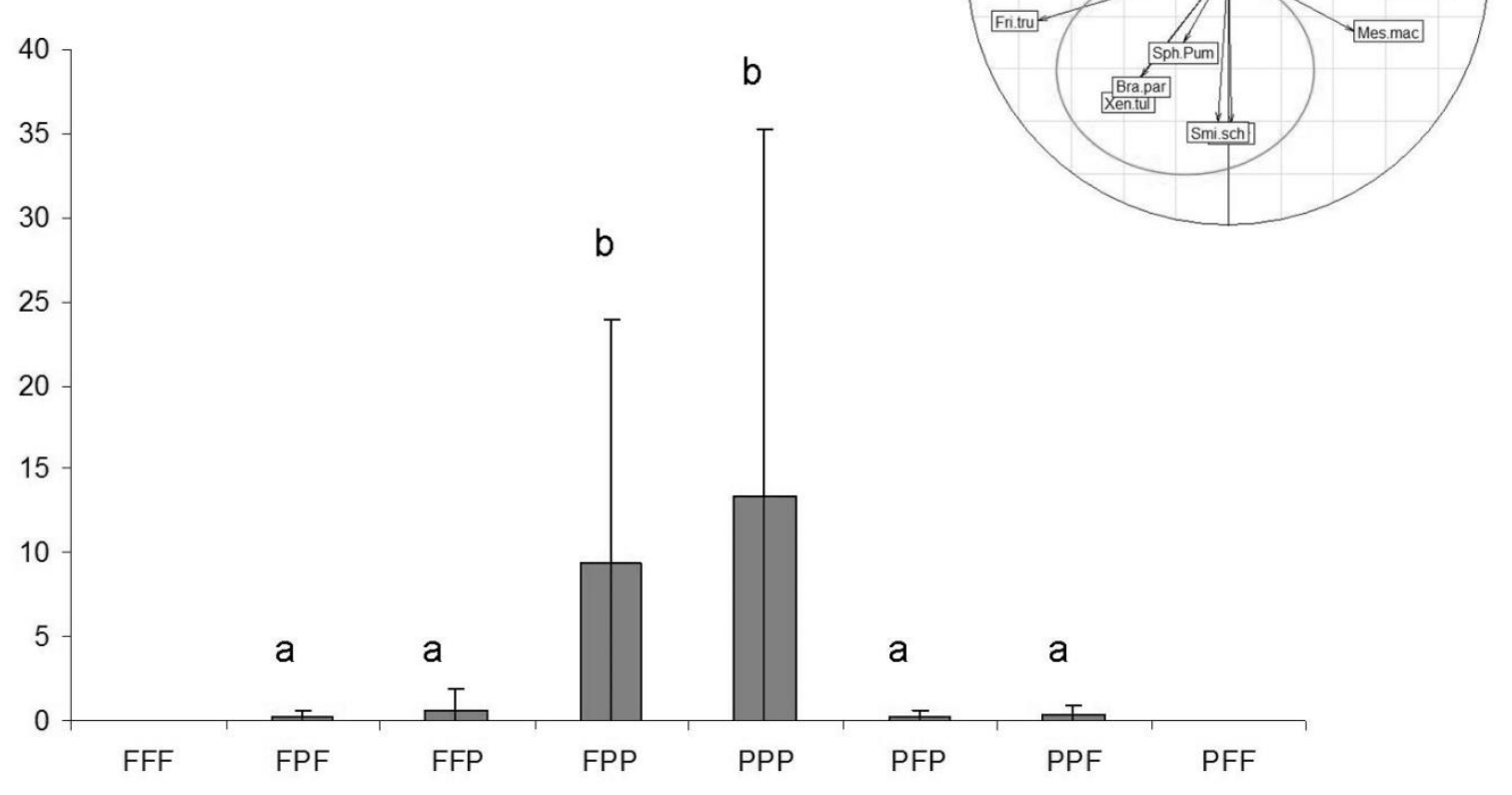

